\title{
Ground-Based Polarimetric SAR Interferometry for the Monitoring of Terrain Displacement Phenomena. Part II: Applications
}

\author{
Rubén Iglesias, Student Member, IEEE, Albert Aguasca, Member, IEEE, Xavier Fabregas, Member, IEEE, \\ Jordi J. Mallorqui, Senior Member, IEEE, Dani Monells, Student Member, IEEE, \\ Carlos López-Martínez, Senior Member, IEEE, and Luca Pipia
}

\begin{abstract}
Urban subsidence and landslides are among the greatest hazards for people and infrastructure safety and they require an especial attention to reduce their associated risks. In this framework, ground-based synthetic aperture radar (SAR) interferometry (GB-InSAR) represents a cost-effective solution for the precise monitoring of displacements. This work presents the application of GB-InSAR techniques, particularly with the RiskSAR sensor and its processing chain developed by the Remote Sensing Laboratory (RSLab) of the Universitat Politècnica de Catalunya (UPC), for the monitoring of two different types of ground displacement. An example of urban subsidence monitoring over the village of Sallent, northeastern of Spain, and an example of landslide monitoring in El Forn de Canillo, located in the Andorran Pyrenees, are presented. In this framework, the key processing particularities for each case are deeply analyzed and discussed. The linear displacement maps and time series for both scenarios are showed and compared with in-field data. For the study, fully polarimetric data acquired at X-band with a zero-baseline configuration are employed in both scenarios. The displacement results obtained demonstrate the capabilities of GBSAR sensors for the precise monitoring of ground displacement phenomena.
\end{abstract}

Index Terms-Differential synthetic aperture radar (SAR) interferometry (DInSAR), displacement monitoring, groundbased SAR (GB-SAR), frequency modulated continuous wave (FMCW) radar, ground-based SAR interferometry (GBInSAR), persistent scatterer interferometry (PSI), polarimetric SAR interferometry (PolInSAR), steepest linear frequency modulated continuous wave (SLFMCW) radar. HE DEVELOPMENT of differential synthetic aperture radar (SAR) interferometry (DInSAR) algorithms during the last decade has demonstrated their usefulness for the precise monitoring of ground displacement episodes [1], [2] with

Manuscript received March 31, 2014; revised July 22, 2014; accepted September 18, 2014. This work was supported in part by the Big Risk Project (contract number BIA2008-06614), and in part by the Project TEC2011-28201C02-01 funded by the Spanish MICINN and FEDER funds.

R. Iglesias, A. Aguasca, X. Fabegas, J. J. Mallorqui, D. Monells, and C. López-Martínez are with the Department of Signal Theory and Communications, Universitat Politècnica de Catalunya, 08034 Barcelona, Spain (e-mail: ruben.iglesias@tsc.upc.edu; aguasca@tsc.upc.edu; fabregas@tsc.upc.edu; mallorqui@tsc.upc.edu; dmonells@tsc.upc.edu; carlos.lopez@tsc.upc.edu).

L. Pipia is with the Institut Cartogràfic Geològic de Catalunya, 08038 Barcelona, Spain (e-mail: luca.pipia@icc.cat).

Color versions of one or more of the figures in this paper are available online at http://ieeexplore.ieee.org.

Digital Object Identifier 10.1109/JSTARS.2014.2366711 millimetric precisions [3]. Furthermore, DInSAR algorithms have boosted the development of persistent scatterer interferometry (PSI) techniques which allows obtaining not only accurate linear velocity estimations but also time series containing the nonlinear displacement component of affected areas [4]-[15].

In this context, two different kinds of sensors may be considered: orbital/airborne or ground-based. Spaceborne SAR sensors have demonstrated to be extremely successful for studying the evolution of displacement processes, especially, over wide areas. Despite this, when flexibility in terms of revisiting time or sensor orientation toward the scene is required, orbital sensors cannot fulfill the requirements. Airborne sensors represent a more flexible solution but contrarily the data processing becomes more difficult. Furthermore, the monitoring campaigns are generally costly and complex to carry out. For this reason, the research activity of several groups has been recently addressed to the development of terrestrial SAR systems [16], [17]. Flexible, easy to deploy, and cheaper if compared to space- or airborne solutions, Ground-Based SAR (GB-SAR) sensors can be presented as an effective, and sometimes complementary, solution for the precise monitoring of small-scale phenomena [18]-[33].

Due to the capability of GB-SAR sensors to carry out a quasi continuous monitoring, one of their most relevant application corresponds to the slope monitoring of open pit mines, in which such systems potentially work as an Early Warning System (EWS) [34]-[37]. Other relevant applications include slope instability monitoring related to rock-slides [38], [39], [21], volcanoes [40], urban monitoring [41]-[43], structure monitoring [44], [16], dike monitoring [45], glacier monitoring [46], and landslides [43], [45], [47]-[50]. A complete classification of the different GB-SAR applications can be found in [51].

This paper presents the applicability of the RiskSAR GBSAR sensor, developed in the Remote Sensing Laboratory (RSLab) of the Universitat Politècnica de Catalunya (UPC) and widely described in Part I of this paper [52], for the efficient monitoring of ground displacement phenomena.

The RiskSAR sensor [22], [29] is based on the employment of high-rate steepest linear frequency modulated continuous wave (SLFMCW) signals. This type of solution allows performing faster scans compared with vector network analyzer (VNA)-based solutions and, hence, minimize the impact of 
tropospheric disturbances and target instabilities during the scanning time. This radar architecture also favors obtaining reliable polarimetric SAR (PolSAR) measurements with no dramatic increase in the scanning time. In this context, it has been recently demonstrated that polarimetric SAR interferometry (PolInSAR) techniques outperform classical singlepolarization PSI performance [53]-[55].

The applications shown in this work are focused on the GBSAR sensor working in a discontinuous operation mode, which means revisiting the site during different measurement days with a certain temporal span. This can be applied when the deformation process is slow enough and does not require a continuous monitoring. As widely explained in [52], the processing for this configuration mode consists of performing first a temporal averaging of each daily data set. This is referred to as short-term processing (STP) and allows improving the signal-to-noise ratio (SNR) of time-stationary targets, leading to a time-averaged SLC image for each measurement day. In the following step, referred to as long-term processing (LTP), the atmospheric artifacts among the different time-averaged SLC images are compensated for. From all methods available in the literature, the RiskSAR processing chain makes use of model-based solutions to carry out the atmospheric phase screen (APS) compensation. This kind of solution has proven to be very effective since it reaches very good results with no need of extra meteorological data or stable ground control points (GCP). Carrying out a proper APS estimation and compensation process is mandatory in order to obtain reliable displacement map estimations. Once a set of APS-free interferograms are obtained, PSI techniques can be applied to obtain reliable linear and nonlinear estimations of ground displacements. Among all the PSI techniques developed in the last decade, this work focuses on the adaptation of the coherent pixels technique (CPT) to work with zero-baseline data [52].

The linear displacement maps and time series over two very different scenarios, a district affected by subsidence due to the mining activity carried out in the surrounding area during the last century, and an active slow-moving landslide located in a mountainous region, are presented. The main logistics and processing particularities for each case are widely discussed. In both scenarios, the RiskSAR sensor was operated at X-band due to its excellent tradeoff among the high spatial resolution of the SLC images acquired, the possibility to achieve a reliable APS compensation and a fine sensitivity to ground displacements. For this reason, the RiskSAR sensor is referred to as RiskSAR-X hereinafter. The slant-range resolution working at $\mathrm{X}$-band is $1.25 \mathrm{~m}$. The cross-range resolution is on the order of $10 \mathrm{mrad}$, ranging from $0.75 \mathrm{~m}$ at near range up to roughly $5 \mathrm{~m}$ at a far range of $1500 \mathrm{~m}$. In both cases, the processing is benefited from the use of fully polarimetric data.

The paper is organized as follows. Section II refers to GBSAR measurement logistics, with emphasis in the importance of choosing a correct location for the sensor depending on the nature of the scenario and on the ground displacement process characteristics. Sections III and IV present the zero-baseline PSI results in the urban scenario of Sallent and in the landslide of El Forn de Canillo, respectively. The main conclusion and major remarks are given in Section V.

\section{Measurement Logistics}

Once a GB-SAR solution is adopted for the monitoring 143 of a certain area, the location of the sensor constitutes a 144 crucial issue in order to maximize the performance of the 145 technique. In addition to be able to cover the whole area of 146 interest, two important aspects must be taken into account: 147 the minimization of the so-called SAR geometrical distortions 148 (foreshortening, layover, or shadowing) to have the regions of 149 interest visible to the radar, and the maximization of the sen- 150 sor sensitivity to deformation, as SAR systems are only able 151 of detecting displacements in the line-of-sight (LOS) direction. 152 The selection of the adequate emplacement helps to maximize 153 the sensitivity of the interferometric phase to the deforma- 154 tion process to monitor, and thus provide the best results 155 possible.

These aspects must be taken into account when planning the 157 measurements and, furthermore, in the final interpretation of 158 the results. This section presents their analysis in order to max- 159 imize the performance of ground-based SAR interferometry 160 (GB-InSAR) techniques depending on the nature and environ- 161 mental conditions of the displacement phenomenon.

\section{A. Minimization of SAR Geometric Distortion Effects}

Regardless of the platform nature, three geometric distortions are present in SAR imaging. These are the foreshortening, the layover, and the shadowing [56]. Unlike orbital-based SAR sensors, which are constrained by the orbit geometry, GB-SAR sensors allow fitting the sensor location and orientation to the specific characteristics of the area under study. This fact allows to minimize, or at least control, these distortion effects.

Shadowing must be especially taken into account when facing urban monitoring applications. Urbanized areas are typically characterized by having a relatively large number of tall man-made structures, such as buildings. If the location of the sensor is decided without considering its impact, it can lead to a large number of shaded areas in the SAR acquisitions. The location of the instrument at a certain height in order to achieve a top view of the area under study minimizes shadowing impact

Contrarily, landslide areas are typically characterized by having a low numbers of man-made structures. Therefore, shadowing has less impact in these applications. Despite this, it is important to choose a location which allows overcoming the geographical accidents of the scenario. In these areas, foreshortening plays a more critical role. The illumination angle must depart from the local slope to avoid as much as possible the compression effect produced by this geometrical distortion A good strategy consists of locating the instrument at the base of the hillside, some meters away from the slope, in order to illuminate all the area of interest minimizing the shadowing and the foreshortening artifacts.

\section{B. Maximization of the Sensitivity to Deformation}

As stated above, SAR systems only have sensitivity in the 193 LOS direction. Due to its different orientation, the measured 194 
displacements are, in general, not the real ones but a projection of them. Using a vector notation, both can be defined as

$$
\begin{aligned}
\mathbf{V}_{L O S} & =\left|\mathbf{V}_{\mathbf{L O S}}\right| \cdot \widehat{\mathbf{l}}_{\mathbf{L O S}} \\
\mathbf{V}_{G} & =\left|\mathbf{V}_{\mathbf{G}}\right| \cdot \widehat{\mathbf{l}}_{\mathbf{G}}
\end{aligned}
$$

where $\mathbf{V}_{G}$ is the ground displacement vector, this is the real deformation, and $\mathbf{V}_{L O S}$ is the LOS displacement vector, this is the projection. The magnitudes $\left|\mathbf{V}_{\mathbf{L O S}}\right|$ and $\left|\mathbf{V}_{\mathbf{G}}\right|$ are related to the intensity of the displacement, and the unitary vectors $\widehat{l}_{\mathbf{L O S}}$ and $\widehat{\mathrm{l}}_{\mathrm{G}}$ indicate the displacement direction. In fact, the former is only a projection of the latter. Thus, the magnitude of both displacement vectors can be related through a scalar product as follows:

$$
\left|\mathbf{V}_{\mathbf{L O S}}\right|=\left|\mathbf{V}_{\mathbf{G}}\right| \cdot \cos (\alpha)
$$

where

$$
\cos (\alpha)=\widehat{\mathrm{l}}_{\mathbf{L O S}} \cdot \widehat{\mathrm{l}}_{\mathbf{G}}
$$

being $\alpha$ the angle between the unitary vectors.

When the ground displacement is expected to be vertical, as it normally occurs with subsidence phenomena in urban scenarios, $\alpha$ directly becomes the local incidence angle $\theta_{i n c}$. In this context, higher sensor location elevations over the area of interest imply shorter incidence angles and thus a better sensitivity to the ground displacement.

When facing landslide monitoring the problem becomes more complex as the real motion of a particular point has an intrinsic topographic dependence related with its local slope. With no a priori knowledge, the more realistic kinetic model of the displacement direction $\widehat{l}_{\mathrm{G}}$ is based on considering that the surface mostly moves along the steepest gradient of the terrain slope. This information may be derived employing a digital elevation model (DEM) of the area. Then, the angle $\alpha$ is directly obtained through (3).

For the current polar-orbiting SAR satellites, the look direction is close to East or West, for ascending or descending orbits, respectively. For this reason, spaceborne SAR systems are mainly sensitive to movements along slopes facing either East or West and almost insensitive to movements in North or South directions. In this context, GB-SAR sensors present a potential advantage with respect to spaceborne ones since they are not constrained by any orbit geometry. GB-SAR sensors can be placed at an adequate location and fit their orientation for illuminating a specific site according to the geometry of the problem.

A good strategy in landslide monitoring applications consists of locating the instrument at the foot of the hillside, using an illumination angle facing the down-slope direction in order to maximize the displacement detection.

\section{URban Monitoring Study CASE}

Urban monitoring represents one of the most interesting issues and major research topics in the SAR community. Subsidence hazards in urban areas involve from damage in man-made structures to the sudden collapse of entire 241 neighborhoods, thus endangering human lives. Two surveying 242 methods are mainly used for ground deformation monitoring 243 purposes over urban scenarios. These are leveling and global 244 positioning system (GPS). In most cases, the difficulty to cover 245 large areas and the poor densities of measurements provided 246 by these techniques hinder the effective identification and char- 247 acterization of complex deformation episodes. Geotechnical 248 devices such as inclinometers, extensometers, or piezometers 249 present similar drawbacks.

GB-SAR sensors hence represent a useful alternative with 251 respect to the previous surveying techniques. They provide pre- 252 cise estimations of ground displacement phenomena over larger 253 areas with a high density of measures at a lower cost.

This section presents the study case of a linear urban subsi- 255 dence phenomenon produced in a district affected by the former 256 mining activity carried out around the area.

\section{A. Test Site and Data Set}

The test site selected corresponds to a district known as $E l \quad 259$ Barri de l'Estació, located in the village of Sallent, northeastern 260 Spain. Nowadays, there is a subsidence phenomenon induced 261 by the intense mining activity carried out in the area during the 262 second quarter of the last century. This deformation process is 263 the consequence of the exploitation of the Enrique Mine, which 264 was opened from 1932 to 1973 and reached a maximum depth 265 of $260 \mathrm{~m}$. 266

Unexpectedly, during the intense mining works of 1954, a 267 natural cavity of about $120 \mathrm{~m}$ high and $40 \mathrm{~m}$ wide was found. 268 Some years later, during 1957 and 1962, several floods from the 269 Llobregat River occurred that made difficult to continue with 270 the mine exploitation, and finally leading to the closure of the 271 Enrique Mine in the year 1973.

During the period of abandoning, the mine was filled up with 273 saturated salty water. Some decades after, in 1990s, heavy dam- 274 ages started to be appreciated in several man-made structures 275 built within the affected district of El Barri de l'Estació [see 276 Fig. 1(a)].

As a response to the problem, the administration started a 278 research program to identify, characterize, and model the subsi- 279 dence phenomena observed in the affected area [57]. A multiple 280 set of techniques such as laser topographic leveling, geologi- 281 cal mapping, geophysical prospection, extensometric measure- 282 ments, and drilling was employed to evaluate the risk of the 283 already weakened structures to collapse.

In this framework, the RSLab group, jointly with the Institut 285 Cartogràfic i Geològic de Catalunya (ICGC), started in 2003, 286 the study of this area with PSI techniques using spaceborne 287 acquisitions of the European Remote Sensing (ERS) satellite 288 [58]. A new collaboration between the RSLab and the ICGC 289 started in 2006 to assess the performance of GB-SAR sensors 290 in such scenarios. A 1-year measurement campaign was carried 291 out using the RiskSAR-X sensor [22], [29]. It started in June 292 2006 and finished in March 2007. GB-SAR data were acquired 293 during nine measurement days, as reported in Table I. In each 294 measurement day, several scans were carried out in order to 295 improve the SNR of measures. 




(a)



(b)

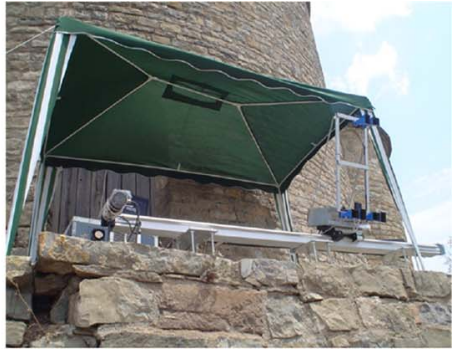

(c)

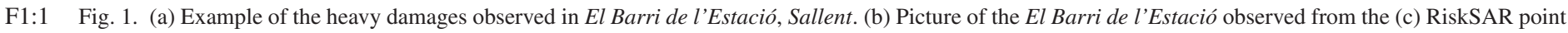
$\mathrm{F} 1: 2$ of view.

$\mathrm{T} 1: 1$

T1:2
TABLE I

Timetable of Sallent Measurement Days

\begin{tabular}{ccccc}
\hline Campaign & $\begin{array}{c}\text { Date } \\
\text { dd/mm/yyyy }\end{array}$ & $\begin{array}{c}\text { Start Time } \\
\text { hh:mm }\end{array}$ & $\begin{array}{c}\text { Stop Time } \\
\text { hh:mm }\end{array}$ & Numb. of Scans \\
\hline 1 & $29 / 06 / 2006$ & $11: 00$ & $16: 00$ & 27 \\
2 & $26 / 07 / 2006$ & $08: 00$ & $11: 30$ & 30 \\
3 & $19 / 08 / 2006$ & $10: 40$ & $16: 00$ & 39 \\
4 & $20 / 10 / 2006$ & $09: 40$ & $15: 00$ & 31 \\
5 & $14 / 11 / 2006$ & $12: 30$ & $16: 30$ & 41 \\
6 & $28 / 11 / 2006$ & $19: 00$ & $08: 40$ & 44 \\
7 & $18 / 12 / 2006$ & $20: 45$ & $05: 00$ & 49 \\
8 & $13 / 02 / 2007$ & $22: 00$ & $09: 55$ & 37 \\
9 & $14 / 03 / 2007$ & $20: 00$ & $09: 50$ & 41 \\
\hline
\end{tabular}

\section{B. System Setup}

As seen in Section II, in urban monitoring applications, the GB-SAR location must minimize as far as possible the effects produced by the buildings present in the scenario. This implies to select an emplacement as high as possible in order to have a top view of the area of interest, which minimizes the shadowing and maximizes the sensitivity to vertical displacements.

For these reasons, the instrument was finally installed on the top of a cliff of $84 \mathrm{~m}$ height, $200 \mathrm{~m}$ away in the range direction from the district El Barri de l'Estació. This location provided an incidence angle varying from $72^{\circ}$ up to $82^{\circ}$. It is worth pointing out that installing the radar on the cliff's border prevented the radar front-end of saturations caused by close targets. Moreover, the system was placed on a base at approximately $30 \mathrm{~cm}$ above the ground to raise the rail and reduce the impact of the nearby vegetation.

Another important issue was to ensure a millimetric repositioning of the instrument to avoid a later coregistration of the data. In order to guarantee the repeatability of the observation conditions, the system was mounted over a cement base reinforced with a lightweight metallic frame. A picture of the RiskSAR-X point of view, and the final system setup is detailed in Fig. 1(b) and (c), respectively.

The area of interest illuminated by the RiskSAR sensor extended to approximately $400 \mathrm{~m}$ in range and $300 \mathrm{~m}$ in width. Each scan took roughly $2.5 \mathrm{~min}$ to perform a fully polarimetric measure.

\section{Short-Term and Long-Term Processing}

Prior to the application of the zero-baseline CPT algorithm to 326 obtain PSI results, some important aspects about the STP and 327 LTP [52] processing should be briefly remarked.

As seen, El Barri de l'Estació is an urban area plenty of man- 329 made structures. For this reason, the reflectivity image of the 330 region covered by the sensor has a large dynamic range, with 331 strong reflectivity peaks corresponding to man-made structures, 332 see Fig. 2(a). The coherence in these scenarios remains very 333 high along the temporal axis, as illustrated in Fig. 2(b) and (c), 334 which shows the coherence maps from two acquisitions with 335 a temporal baseline of $15 \mathrm{~min}$ and 23 days, respectively. As 336 shown, the highest coherence pixels are preserved in those areas 337 with higher reflectivity, coinciding with the man-made struc- 338 tures present in the scenario. This fact is of crucial importance, 339 since it will lead to a robust network of temporally coherent 340 scatterers in the later PSI processing.

As it is detailed in [52], in addition to the thermal noise 342 and the temporal decorrelation phenomena, APS represents the 343 most relevant distortion artifact on the interferometric phase. 344 It directly impacts in the STP, which aims to obtain a reliable 345 high-quality time-averaged image from each measurement day. 346 In addition, it also affects the LTP, whose objective is obtain- 347 ing a collection of APS-free interferograms for the later PSI 348 processing. From all the available methods, the RiskSAR sen- 349 sor makes use of model-based solutions [59], [60] since they 350 proved to be very successful with no extra meteorological data 351 or stable GCP.

Fig. 2(d)-(f) shows the interferometric phase evolution due 353 to APS between images separated by temporal spans of $15 \mathrm{~min}, 354$ $1 \mathrm{~h}$, and $4 \mathrm{~h}$, respectively. In such regions, the atmospheric 355 artifacts are smooth in both the spatial and temporal domains. 356 The linear approximation proposed in [59] is sufficient to 357 deal with the APS problematic in these scenarios with soft 358 topography [52].

In order to illustrate the good performance of APS model- 360 based solutions in urban scenarios, the compensation process 361 of an interferogram with a temporal span of $2 \mathrm{~h}$ is presented in 362 Fig. 3. With the goal of generating a reliable vector of observa- 363 tions to carry out the linear regression, only the points with the 364 highest coherence values $(\gamma>0.95)$ are employed. In order to 365 estimate the coherence a $9 \times 9$ multilook is selected. Black dots 366 represent the projection onto the range axis of the interferomet- 367 ric phase. Notice how, as expected, the interferometric phase 368 




(a)



(d)

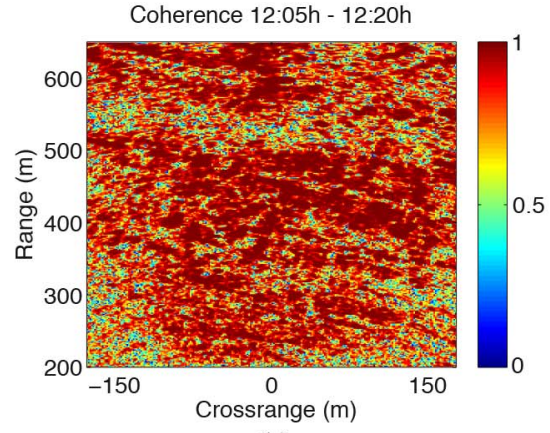

(b)

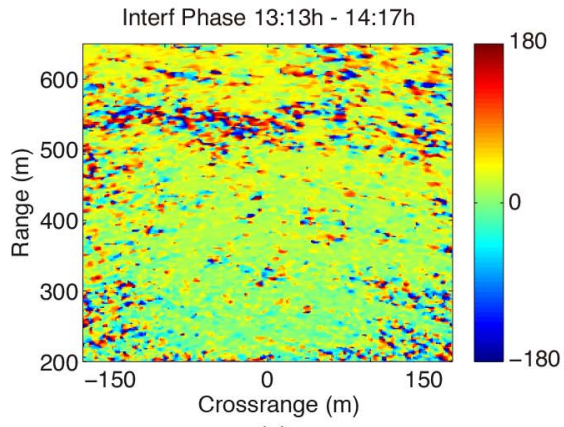

(e)

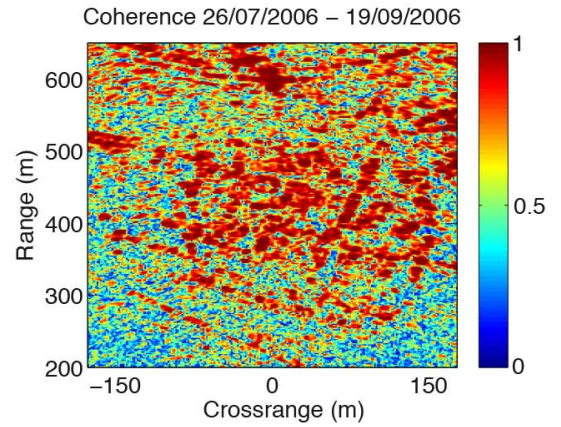

(c)

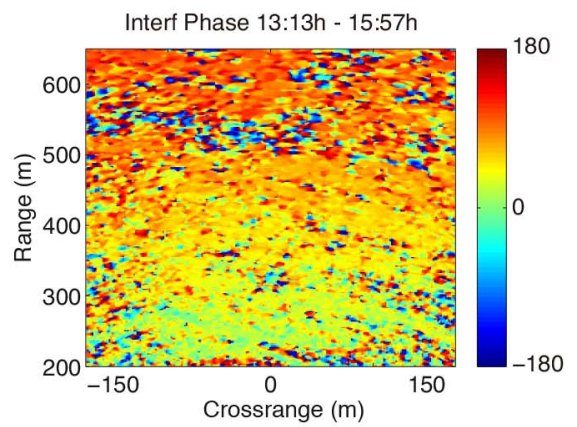

(f)

F2:1 Fig. 2. (a) Reflectivity image in $\mathrm{dB}$ and coherence maps between acquisitions with a temporal baseline of (b) 15 min and (c) 23 days corresponding to the area of F2:2 El Barri de l'Estació, Sallent. Interferometric phase due to the APS between images separated in time (d) 15 min (e) $1 \mathrm{~h}$, and (f) $4 \mathrm{~h}$ approximately.

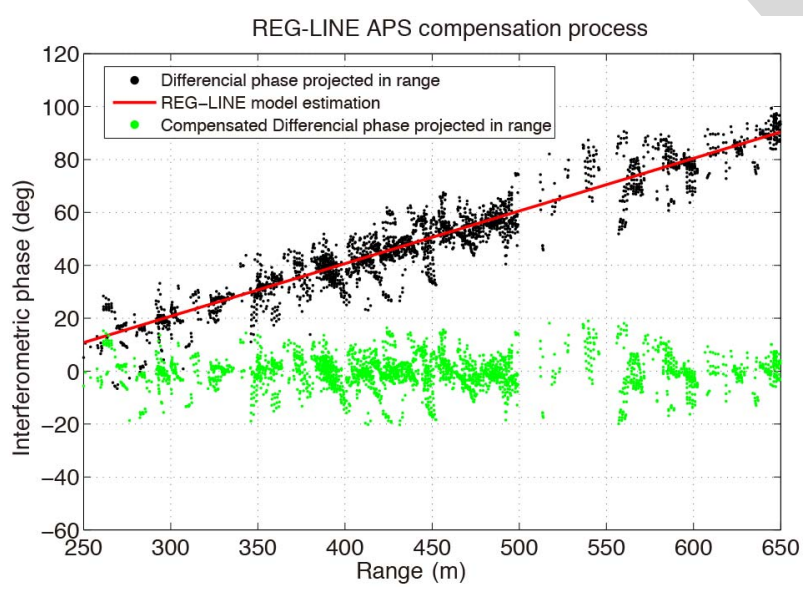

F3:1 Fig. 3. Compensation process of an interferogram with a temporal span of $2 \mathrm{~h}$ F3:2 over those points with a coherence value over 0.95. Black dots represent the F3:3 projection of the interferometric phase onto the range axis. Red line accounts F3:4 for the estimated APS using a linear regression. Green dots correspond to the F3:5 interferometric phase once it has been compensated for. exhibits a strong linear behavior in the range direction. The red line represents the estimated APS using the linear regression method indicated in [52] and [59]. Finally, the green dots correspond to the compensated interferometric phase. Notice how the final interferometric phase has a mean value close to zero. This value is normal since during this short temporal span the interferometric phase may be considered totally independent of any deformation process. In other words, within the same measurement day no detectable movements are expected. Indeed, the interferometric phase of APS-free interferograms has a mean value close to zero.
Due to the large number of high-coherent scatterers available 380 in urban scenarios, the basis-based method explained in [52], 381 which uses a set short-time compensation functions between 382 consecutive daily temporal-averaged images, is not required. 383 Exploiting polarimetry at this point is not necessary for the 384 same reason as well. 385

Finally, in order to reduce the effects of urban target short- 386 time instability induced by human activities, the sample selec- 387 tion technique proposed in [61] is employed for the generation 388 of time-averaged SLC images. The detection of the long-term 389 polarimetric behavior providing the highest number of samples 390 for each day of measurements guaranteed a higher quality of 391 the final interferometric phase information.

\section{Displacement Results}

The displacement map retrieval process is carried out with 394 the zero-baseline adaptation of the CPT algorithm [52]. The 395 choice of the pixel selection method depends on the number 396 of acquisitions at disposal and on the nature of the scatterers to 397 detect, either distributed or point-like scatterers. For this case, 398 since the number of images available is short, only 9, the coher- 399 ence stability criterion has demonstrated to perform well. A 400 threshold of mean coherence corresponding to 0.7 , which is 401 equivalent to a phase standard deviation of about $15^{\circ}$, with a 402 $5 \times 5$ multilook window [62], has been established in order to 403 filter out the noisy pixels from the processing. In this type of 404 urban scenarios, a $5 \times 5$ multilook window has demonstrated a 405 good performance to detect man-made structures. 406

At this point, the processing has been benefited by the 407 use of polarimetric optimization techniques [52]. In particular, 408 
the equal scattering mechanism (ESM) polarimetric optimization method [54] has been selected to improve the quality of interferograms. This is translated in roughly a twofold increase in the number of pixels during the pixel selection step.

Finally, the linear velocity map retrieved using the zerobaseline CPT technique is projected over the vertical as indicated in Section II.

The PSI results obtained with the RiskSAR-X sensor are compared with the results provided by the experts of the ICGC [see Fig. 4(a) and (b)], respectively. On the hand, the groundtruth information was obtained by means of a continuous laser topographic levelling system that monitored a set of positions, indicated as dots in Fig. 4(b), during the same period of the GB-SAR campaign. This discrete set of measurements has been employed to obtain the result provided in the same figure through interpolation. On the other hand, due to the high number of high-coherent pixels in the area, GB-SAR results have also been interpolated in order to ease the comparison with the ground-truth available. A high agreement concerning the spatial description of the deformation process may be observed between both techniques. Notice how the position of the area characterized by the maximum deformation bowl perfectly matches. Despite this, it must be pointed out that GB-SAR measurements lead to a slight overestimation of the displacement rate in the center of the deformation focus, $5 \mathrm{~cm} /$ year against the $4.5 \mathrm{~cm} /$ year given by the in situ ground-truth measurements. The difficulty to install the instrument at a higher elevation, to reach shorter incidence angles and maximize the detection in the LOS direction, could explain this slight discrepancy.

Fig. 4(c) shows the time series of a coherent scatter located in the maximum deformation bowl of the area. A strong linearity, as expected from ground-truth measurements and from the spaceborne results available [57], [58], may be observed.

\section{LAndslide Monitoring Study CASE}

Due to the all-weather and day-night capability to accurately detect ground and surface deformations, GB-InSAR has become a useful tool for geo-hazard assessment during the last few years. The accurate monitoring of landslide surfaces represents an important issue in order to achieve a better understanding of landslide mechanisms, and detecting its potential risks to ensure the safety of people living in such areas.

Traditionally, landslide monitoring has been carried out employing different geotechnical devices, including inclinometers, extensometers, piezometers, and GPS differential networks. These in-field measurements present, in general, a benchmark density and a lower extent compared with SAR techniques. In addition, they require the installation of devices directly onto the landslide surface, which can be a problem when the accessibility to the area is complex. The development of remote sensing monitoring tools based on SAR data is becoming an important issue for many authorities in order to ensure the safety of people living in such areas.

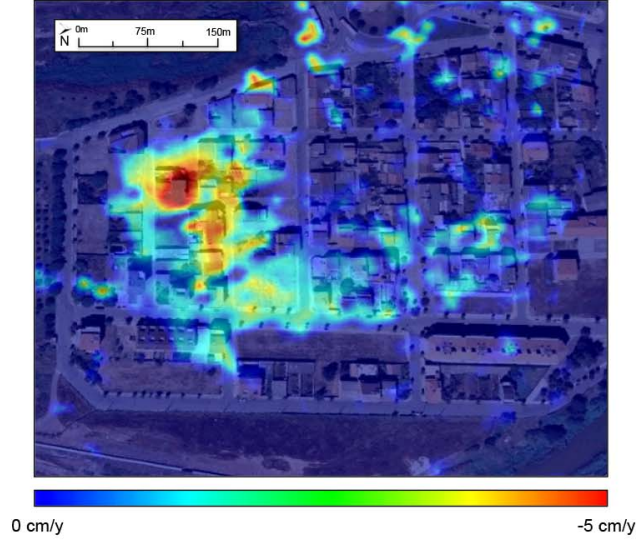

(a)

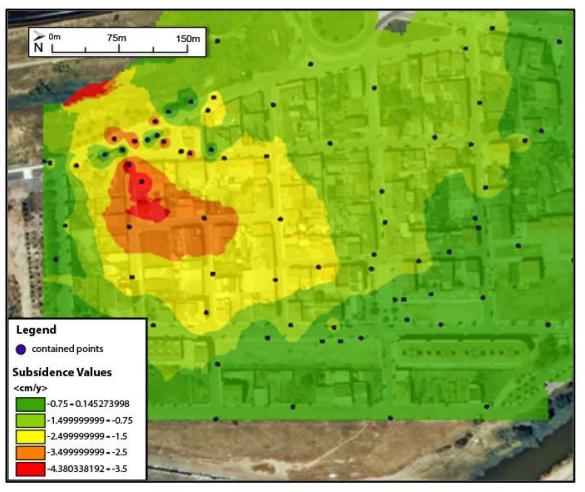

(b)



(c)

Fig. 4. (a) Vertical linear displacement map retrieved by using the zero-baseline F4:1 CPT algorithm. (b) Ground-truth map provided by the ICGC employing laser F4:2 topographic leveling techniques. (c) Displacement time series of a point located F4:3 in the center of the deformation focus with a linear velocity of $4.7 \mathrm{~cm} / \mathrm{year} . \quad$ F4:4

\section{A. Test Site and Data Set}

The test site selected to demonstrate the applicability of GB- 466 SAR sensors in these applications corresponds to the landslide 467 of El Forn de Canillo, located in the Andorran Pyrenees. It 468 has been widely studied since 1980s, and today it is consid- 469 ered as one of the largest landslides of the Pyrenean region [see 470 Fig. 5(a)].

The landslide is composed by a sequence of slides and earth- 472 flows with a complex structure, which affects an estimated mass 473 


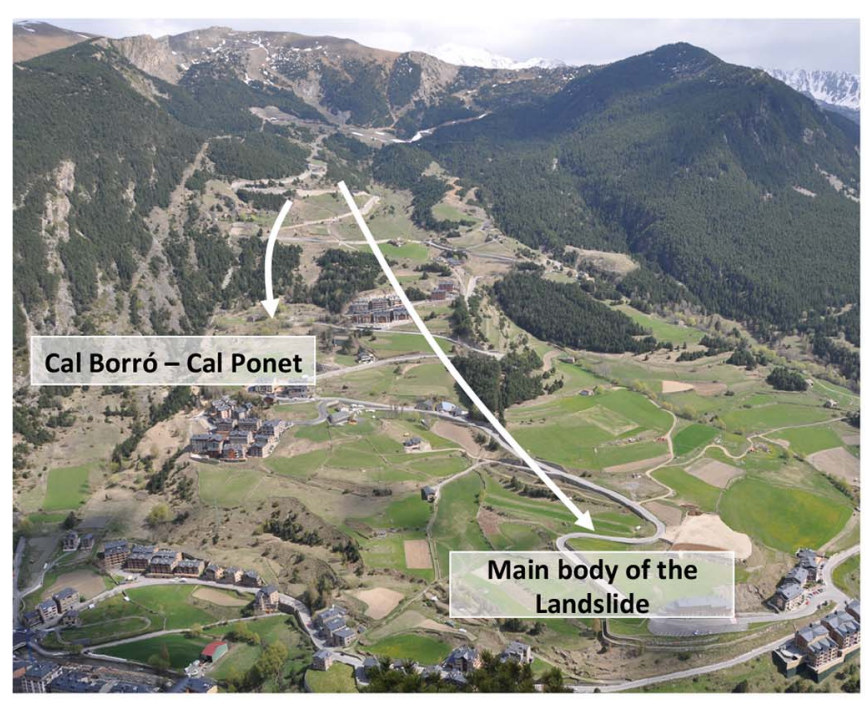

(a)

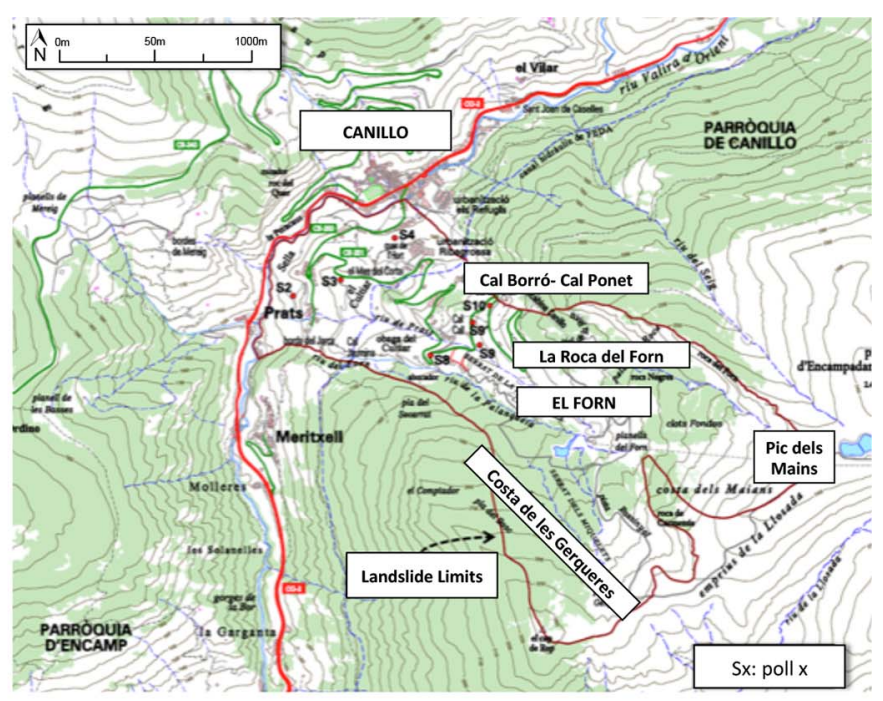

(b)

F5:1 Fig. 5. (a) General overview of the landslide of El Forn de Canillo. (b) Landslide limits and location of the devices installed.

at around $300 \mathrm{Mm}^{3}$. In this context, three major sliding units were identified in 1994 [63]. The first one corresponds to a slide originated in the area of Pla del Géspit-Costa de les Gerqueres [Fig. 5(b)], located in the south-west of the landslide, which reached the foot of the hillside. A second unit was originated under El Pic de Maians [see Fig. 5(b)] reaching a height of $1640 \mathrm{~m}$, and that overlaps with the previous sliding unit, closing in the Valira River valley. Finally, a new rotational slide with a lower extension originated on the hillside known as La Roca del Forn [see Fig. 5(b)] in the north-east side of the hillside has been identified.

The landslide of El Forn de Canillo was originated as the result of the hillside destabilization, due to a decompression phenomenon after the removal of the Valira Glacier, between 13000 and 16000 years before present [63]. The Valira River has been progressively eroding the base of the whole mass without reaching the bedrock, and thus originating the landslide.

The geological observations accumulated during the last decades have evidenced the presence of a main slide mass with a residual movement of some millimeters per year, accompanied by a local failure in the area known as Cal-Ponet Cal-Borró [see Fig. 5(b)] within the third slide unit described above. This slide is presenting today a major activity coinciding with periods of strong rainfalls and snow melting.

In front of all these evidences, the authorities promoted several actions in the year 2000 for the management of the risk related with the geo-hazard threats associated with landslides, rockfalls, and debris flows in the Andorran Pyrenees. Some specific management plans were carried out for the monitoring of El Forn de Canillo.

Between 2007 and 2009, a complex network of geotechnical devices, including inclinometers, rod extensometers, and piezometers, was installed in order to characterize and understand the dynamics of the landslide. A total of 10 boreholes, referred from $S 1$ to $S 10$ in Fig. 5(b), reaching a depth between 40 and $60 \mathrm{~m}$, were drilled and equipped with this instrumentation. The measurements provided by these devices 511 have been recently studied with the objective of locating the 512 sliding surfaces and characterizing the displaced material [64]. 513

Unfortunately, some of the boreholes did not reach the 514 needed depth, and consequently the installed devices did not 515 work properly in some points. Despite this, as it has been 516 expected from in situ observations, the installed devices evi- 517 denced that, in addition to a residual movement of the main lobe 518 of some millimeters per year, the most active part of the land- 519 slide corresponds to the secondary landslide of Cal Borró-Cal 520 Ponet, which between May and June 2009 registered a velocity 521 up to roughly $2 \mathrm{~cm} /$ month [64]. Intense rain events and sudden 522 snow melting was observed during this period. As an example, a 523 famous house built in the mid-19th century, located next to the 524 foot of this secondary landslide near to S10, has experienced 525 a significant damage [see Fig. 6(a)]. Several cracks and shear 526 openings along the road pavements close to this area have also 527 appeared over the last years [see Fig. 6(b)].

In 2011, the use of GB-InSAR techniques to identify and 529 characterize the dynamics of the landslide were planned. The 530 reasons were twofold: on the hand, most of the geotechnical 531 devices implemented did not work properly providing unreli- 532 able measures and, on the other hand, conventional geotechni- 533 cal field measurements present lower densities and thus a worse 534 coverage compared with SAR techniques. For this reason, the 535 RSLab, in collaboration with the Department of Geotechnical 536 Engineering and Geosciences of the UPC, carried out a 1-year 537 measurement campaign, from October 2010 to October 2011, 538 with the objective of identifying and characterizing the behavior 539 of the landslide.

Since the landslide of El Forn de Canillo is nowadays quite 541 stable with some residual movement of the order of few cen- 542 timeters per year, a continuous monitoring was considered 543 clearly unfruitful. For this reason, a total of 10 daily data 544 sets were collected with a temporal base line of approximately 545 1 month, performing thus a discontinuous monitoring, sufficient 546 to avoid phase unwrapping (see Table II). 


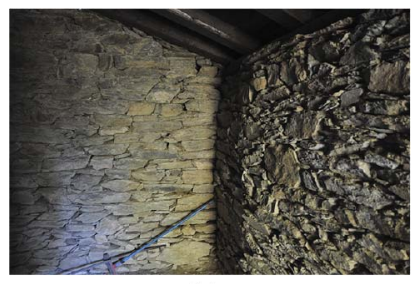

(a)

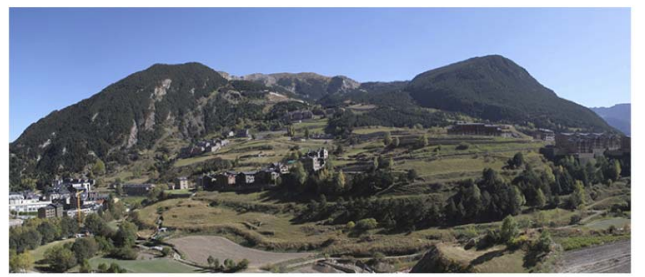

(c)

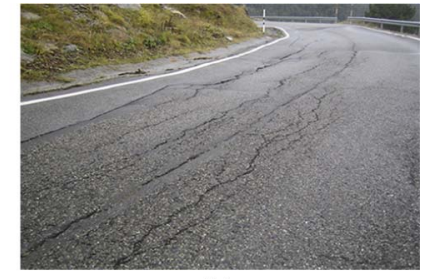

(b)

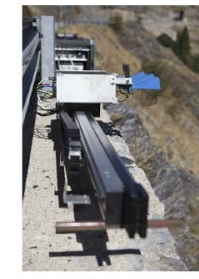

(d)
F6:1

F6:2

F6:3

$\mathrm{F} 6: 4$

F6:5

F6:6

T2:1

T2:2
Fig. 6. (a) Interior view of the cracked walls of a small farmhouse located in the area of Cal Borró-Cal Ponet. The curved shape of the wall indicate the presence of displacements in this area. (b) Cracks and shear openings along a road pavement close to the area of Cal Borró-Cal Ponet. (c) Panoramic view of El Forn de Canillo, in the Andorran Pyrenees from (d) the RiskSAR point of view

TABLE II

Timetable of El Forn de Canillo Measurement Days

\begin{tabular}{ccccc}
\hline Campaign & $\begin{array}{c}\text { Date } \\
\text { dd/mm/yyyy }\end{array}$ & $\begin{array}{c}\text { Start Time } \\
\text { hh:mm }\end{array}$ & $\begin{array}{c}\text { Stop Time } \\
\text { hh:mm }\end{array}$ & Numb. of Scans \\
\hline 1 & $21 / 10 / 2010$ & $09: 57$ & $12: 08$ & 15 \\
2 & $18 / 11 / 2010$ & $17: 04$ & $19: 13$ & 24 \\
3 & $09 / 02 / 2011$ & $17: 00$ & $19: 48$ & 33 \\
4 & $07 / 04 / 2011$ & $18: 17$ & $23: 30$ & 60 \\
5 & $06 / 05 / 2011$ & $10: 02$ & $11: 47$ & 22 \\
6 & $25 / 05 / 2011$ & $16: 09$ & $20: 08$ & 50 \\
7 & $09 / 06 / 2011$ & $13: 20$ & $16: 32$ & 51 \\
8 & $05 / 07 / 2011$ & $08: 25$ & $12: 24$ & 52 \\
9 & $06 / 09 / 2011$ & $11: 49$ & $04: 05$ & 88 \\
10 & $05 / 10 / 2011$ & $11: 57$ & $16: 42$ & 66 \\
\hline
\end{tabular}

\section{B. System Setup}

The RiskSAR-X sensor was located at the foot of the landslide, $100 \mathrm{~m}$ away from the slope, in order to reduce the foreshortening and to maximize the detection of the deformation considering that the landslide moves along the steepest gradient of the terrain slope, as seen in Section II. This emplacement also allows overcoming the geographical accidents of the scenario in order to avoid shadowing in SAR images.

The final area of observation was approximately $500 \mathrm{~m}$ in height, $1600 \mathrm{~m}$ in range, and $1000 \mathrm{~m}$ in width. In addition, as in the urban monitoring case, the system was placed on a base at the height of approximately $30 \mathrm{~cm}$ above the ground, to level the rail and avoid the impact of the nearby vegetation in the measurements. As in the previous study case, each scan took roughly $2.5 \mathrm{~min}$ to perform a fully polarimetric measure.

A picture of the RiskSAR-X point of view and the sensor's location is detailed in Fig. 6(c) and (d), respectively.

\section{Short-Term and Long-Term Processing}

Regarding the characteristics of the scenario, El Forn de 568 Canillo is mainly covered by vegetation and only contains some 569 man-made structures and few rocky areas suitable to perform 570 a reliable GB-InSAR processing. The reflectivity image of the 571 region covered by the RiskSAR-X sensor is shown in Fig. 7(a). 572 Fig. 7(b) and (c) shows the coherence maps of image pairs with 573 a temporal baseline of $13 \mathrm{~min}$ and $6 \mathrm{~h}$, respectively.

Notice how the high-reflectivity areas generally correspond 575 to those pixels with higher coherence values, as expected. These 576 pixels belong to man-made structures, rocky areas, or bare sur- 577 faces. Notice also how coherence decreases faster on vegetated 578 areas at X-band, and how only man-made structures or rocky 579 areas remain coherent along time. A considerable loss of coher- 580 ence in only $6 \mathrm{~h}$ can be noticed. Preserving high-coherent pixels 581 along time is a critical issue in these vegetated scenarios, as seen 582 hereinafter.

As in the urban subsidence study case, some important 584 aspects about the STP and LTP [52] processing must remarked 585 prior applying PSI techniques.

Regarding the APS, contrarily to the study case of urban 587 areas seen above, mountainous regions present severe atmo- 588 spheric phase fluctuations, mainly due to the presence of steep 589 topography. Those regions exhibit strong fluctuations of the 590 atmospheric parameters such as temperature, pressure, and 591 humidity from acquisition to acquisition. Due to this reason, the 592 spatial homogeneity assumption, fulfilled in the previous case, 593 does no longer apply. This fact produces the refractivity index to 594 change in both, the spatial domain, mainly due to the changes 595 in the height, and the temporal one, mainly due to the more 596 extreme atmospheric conditions. The linear-regression model, 597 seen in the urban study case needs to be updated with a second- 598 order term related with the product of range distance and height 599 [52], [60].

In order to illustrate that problem, Fig. 7(d)-(f) is presented. 601 This figure shows the temporal evolution of the interferomet- 602 ric phase after only $1 \mathrm{~h}$. Severe atmospheric phase fluctuations, 603 highly correlated with the steep topography of the scenario, 604 appear in just $1 \mathrm{~h}$ leading to over one-cycle phase variations 605 [see Fig. 7(f)].

Fig. 8 shows how the linear-regression model used in the 607 urban study case is not sufficient to compensate for the APS 608 in these scenarios. The compensation process for this exam- 609 ple is carried out over an interferogram with a temporal span 610 of only $1 \mathrm{~h}$. The black dots represent the projection of the 611 interferometric phase onto the range axis in the pixels of the 612 image with higher coherence values $(\gamma>0.95)$. Notice how 613 the interferometric phase does no longer exhibit a linear behav- 614 ior in the range direction. The red line represents the estimated 615 APS using a linear regression, which considerably departs from 616 the interferometric phase, especially at the near and far range. 617 The blue points refer to the new model, indicated in [52] and 618 [60], which accounts for the height of the scenario. Notice 619 how it perfectly fits the interferometric phase trend. Finally, 620 the green dots correspond to the interferometric phase after the 621 compensation process showing the goodness of the proposed 622 technique. 


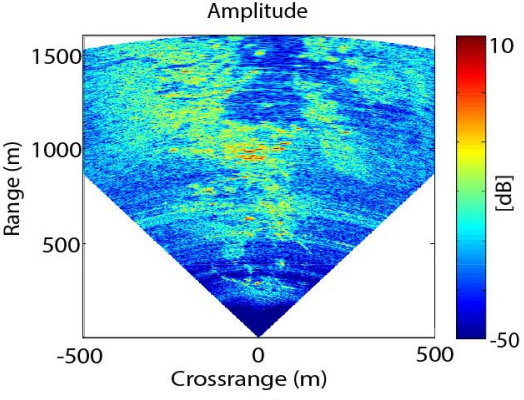

(a)

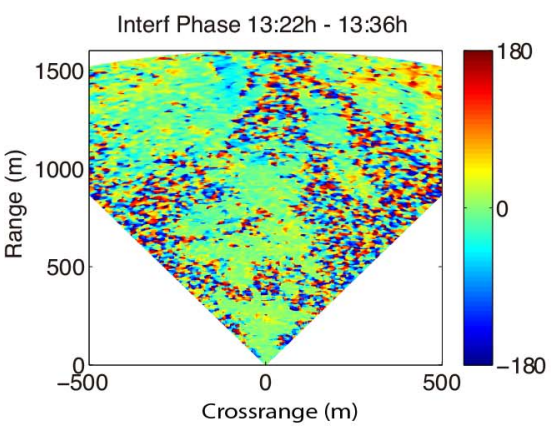

(d)

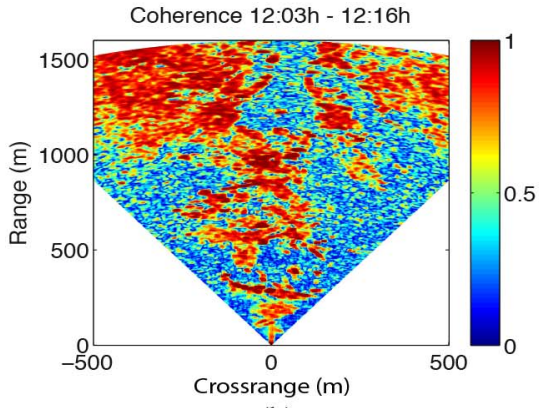

(b)

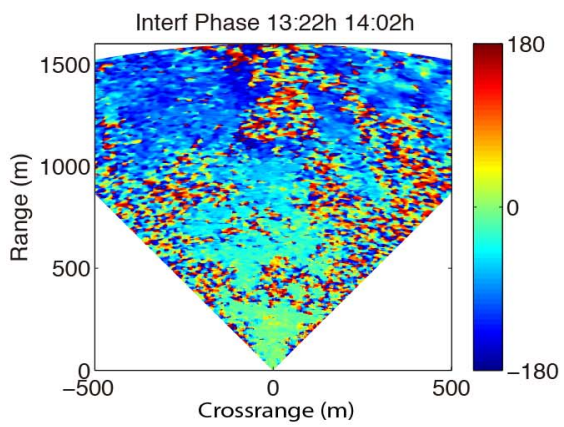

(e)

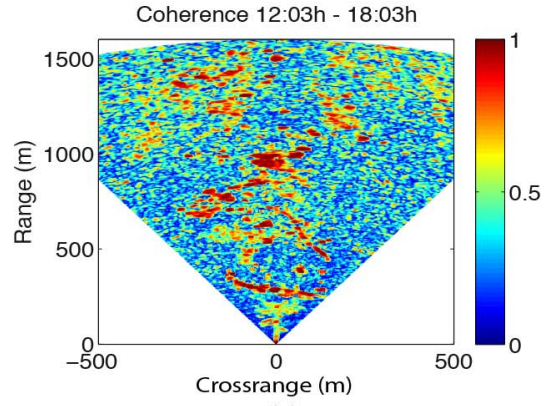

(c)

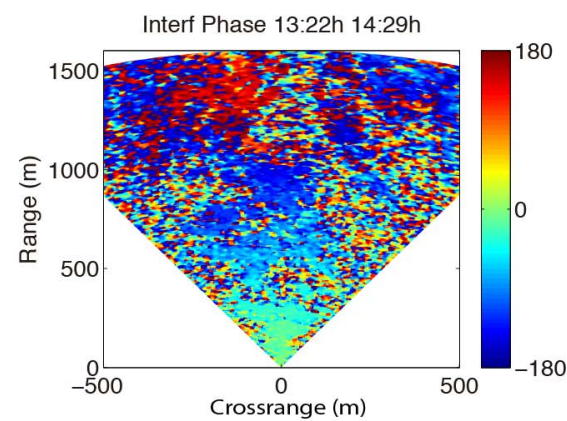

(f)

F7:1 Fig. 7. (a) Reflectivity image in $\mathrm{dB}$ and coherence maps between acquisitions with a temporal baseline of (b) 13 min and (c) $6 \mathrm{~h}$ corresponding to the area of F7:2 El Forn de Canillo, Andorra. Interferometric phase due to APS between images separated in time (d) 15 min (e) $30 \mathrm{~min}$, and (f) $1 \mathrm{~h}$ approximately.

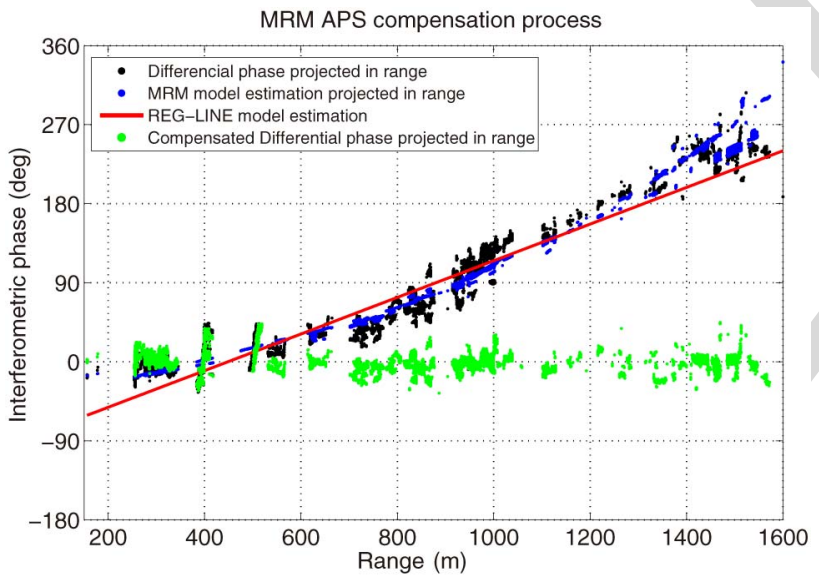

F8:1 Fig. 8. Compensation process of an interferogram with a temporal span of $1 \mathrm{~h}$ F8:2 over those points with a coherence value over 0.95. Black dots represent the F8:3 projection of the interferometric phase onto the range axis. Red line accounts F8:4 for the estimated APS using a linear regression. Blue dots refer to the estimated F8:5 APS using a multiple regression model that takes into account the height of the F8:6 scenario. Green dots correspond to the interferometric phase once it has been F8:7 compensated for.
Fig. 9 illustrates the good performance of the APS compensation technique along time. This figure presents the phase evolution of a coherent scatterer $(\gamma=0.97$ using a $9 \times 9$ multilook) along a total of 70 measures collected during $12 \mathrm{~h}$, from 1:00 P.M. to 1:25 A.M., every $10 \mathrm{~min}$. The dotted line refers to the phase evolution before applying the APS compensation step meanwhile, the solid one accounts for the phase evolution once the APS is compensated. Since all the measures belong to the same measurement day, it is expected an

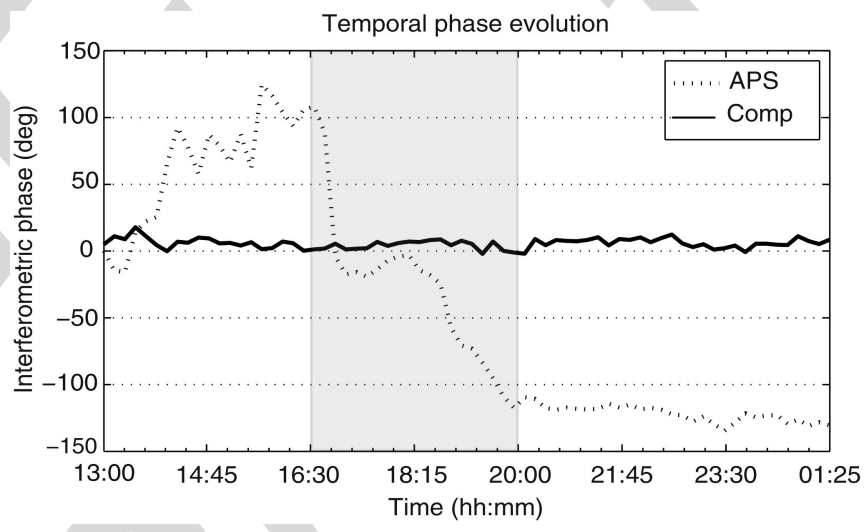

Fig. 9. Phase evolution of a coherent scatterer $(\gamma=0.97$ using a $9 \times 9$ mul- F9: 1 tilook) along 70 measures collected during $12 \mathrm{~h}$, from 1:00 P.M. to 1:25 A.M., F9:2 every $10 \mathrm{~min}$. The dotted line refers to the phase evolution before applying the F9:3 APS compensation step. The solid line accounts for the phase evolution once F9:4 the APS is compensated for. The shaded area accounts for the sunset period, F9:5 coinciding with the more severe APS fluctuations.

absence of movement. After performing the APS compensation 633 step, the interferometric phase (solid line) presents a zero-mean 634 value with a low standard deviation value, $\sigma=3.6^{\circ}$, which 635 corresponds to $0.16 \mathrm{~mm}$. This experiment demonstrates the 636 good performance of the technique over these kind of scenar- 637 ios. Fig. 9 also illustrates how the atmosphere fluctuations are 638 more severe during the day, and especially at sunset (shaded 639 area). This fact confirms that the best GB-SAR performances 640 may be achieved measuring at night, especially in these type of 641 mountainous environments. 


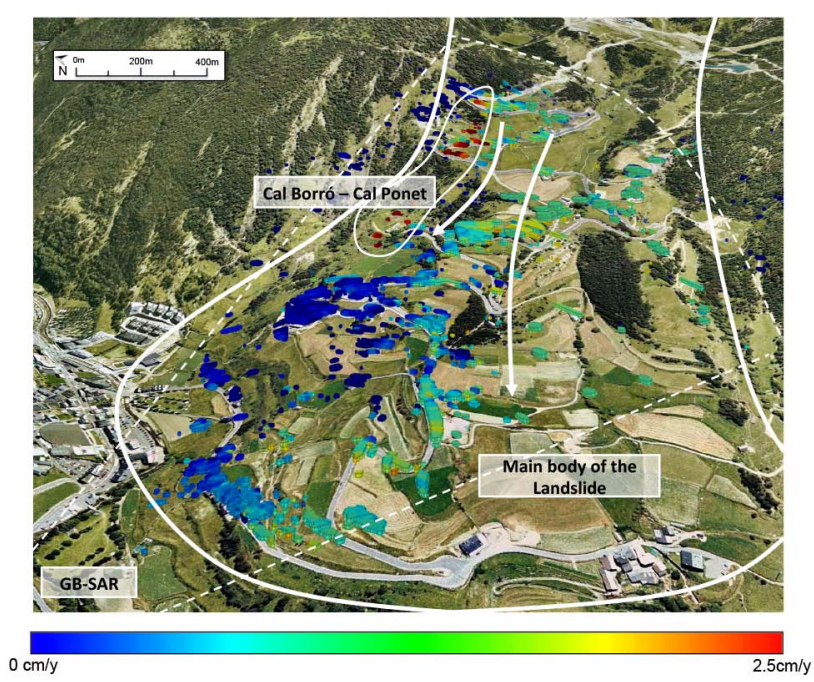

(a)

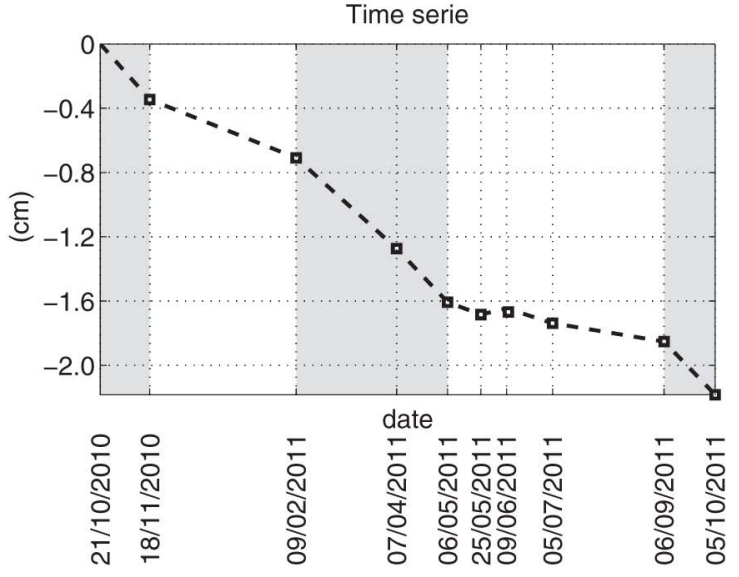

(b)

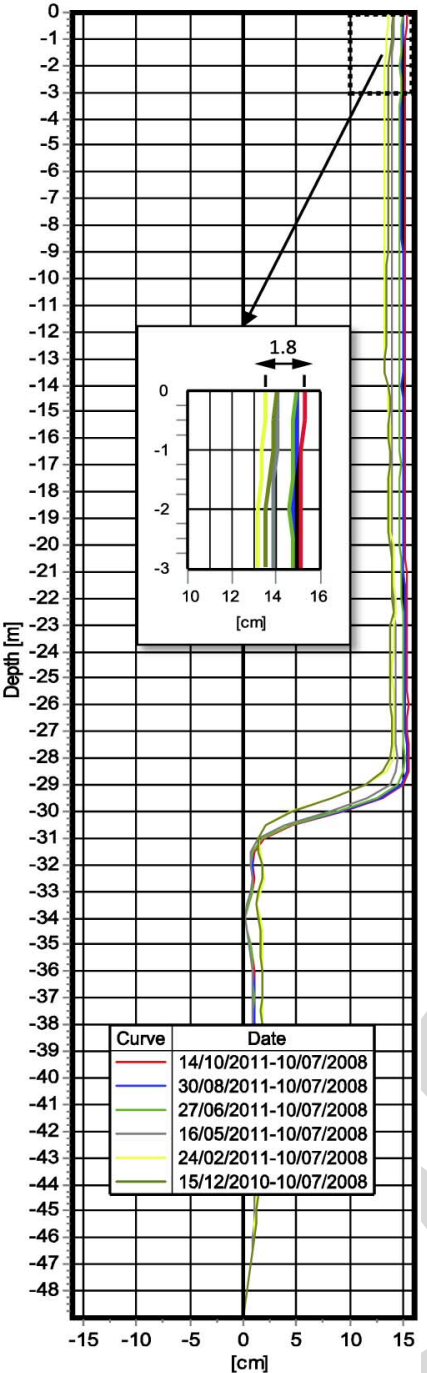

(c)

F10:1 Fig. 10. (a) Geocoded down-slope linear ground-displacement of El Forn de Canillo obtained with the RiskSAR-X sensor covering the period from October 2010 F10:2 to October 2011. (b) Displacement time series of a point located in the area of Cal Borró-Cal Ponet with a linear velocity of $\sim 2.3 \mathrm{~cm} / \mathrm{year}$. The shaded areas F10:3 indicate the periods when the landslide experienced major accelerations. (c) Inclinometric results provided by the firm Euroconsult in the borehole S10, located in F10:4 the area of Cal Borró-Cal Ponet.

At this stage, maximizing the chances of detecting the major number of coherent scatterers available within the area of study is mandatory.

On the one hand, the LTP has been benefited from the use of the compensating function method described in [52]. This method seeks to perform the APS estimation and compensation process using the shortest temporal baselines available in the data set. A basis of short-term compensation functions between consecutive daily temporal-averaged images, characterized by a minimum loss of coherence are first generated. Then, these are employed to compensate for long-term span interferograms.

On the other hand, the LTP may also be benefited from the use of PolSAR data [52], [60]. A simple strategy, which notably increases the number of coherent scatters selected, consists of selecting for each interferogram which needs to be compensated for, the polarimetric channel providing the highest coherence value. This strategy leads to a twofold increase in the 659 number of high-quality pixels during APS compensation step. $\quad 660$

\section{Displacement Results}

The displacement map retrieval is carried out with the zerobaseline adaptation of the CPT technique [52].

Since the number of images available is short, 10 images, the 664 coherence stability criterion is proposed to carry out the pixel 665 selection. This approach performs well even when a reduced 666 number of images are available. Moreover, this pixel selec- 667 tion criterion has demonstrated to be more suited in natural 668 environments with predominance of distributed scatters. $\quad 669$

At this point, since the number of high-quality pixels is 670 smaller for this environment, the zero-baseline CPT algo- 671 rithm is benefited by the use of a multilayer processing [65]. 672 
673 Two thresholds of mean coherence corresponding to 0.7 and 6740.6 are fixed. These correspond to phase standard deviations of 675 about $15^{\circ}$ and $20^{\circ}$, respectively, using a $5 \times 5$ multilook win676 dow [62]. This multilook window maximizes the detection of stable coherent scatters coming from both man-made structures and natural targets, such as rocky areas or bare surfaces.

Furthermore, the ESM polarimetric optimization method [54] has also been employed in order to improve the phase quality of interferograms, and thus achieve a dense network of coherent scatterers to carry out a reliable PSI processing.

Fig. 10(a) shows the final down-slope linear grounddisplacement map geocoded over a Google Earth image, using the zero-baseline CPT algorithm. The result shows a high agreement with the conclusions extracted from the field monitoring campaigns made between 2007 and 2009, presented in [64]. Concretely, the displacement map obtained reveals that the main body of the landslide experienced a residual movement of approximately $1 \mathrm{~cm} /$ month during the period of observation. In the top-left, part of the hillside a local landslide presenting a higher activity $(\sim 2-2.5 \mathrm{~cm} /$ year $)$ may be appreciated. It corresponds to the so-called secondary landslide of Cal BorróCal Ponet, described previously. Fig. 10(b) shows the temporal evolution of a high-coherence point belonging to the maximum displacement rate area. Unlike the urban subsidence case studied previously, which was characterized by a strong linear component, the temporal evolution of the displacement has now a strong nonlinear component. It presents several accelerations and stabilizations during the period of measures. The shaded areas in the figure indicate the periods when the landslide experienced major accelerations. Analyzing the figure in detail, it can be observed that the major displacements are produced in the fall (from October to November 2010) and spring (from February to June 2011), coinciding with the major rainfall and snow melting events. In the last period of the graph (September 2011), coinciding again with autumn's arrival, the landslide seems to accelerate again.

Finally, Fig. 10(c) shows the inclinometric results provided by the firm Euroconsult in the borehole S10, located in the maximum deformation rate area of Cal Borr-Cal Ponet. The figure illustrates a horizontal profile of the deformed shape of the inclinometer casing along the borehole depth in the down-slope direction for different dates. The curves correspond to the period corresponding from December 2010 to October 2011, and all are referred to July 2008. The S-shaped plot reflects that the main shear band is located about $30 \mathrm{~m}$ under the surface of the landslide. In order to ease the comparison of the inclinometric results with the ones obtained with the GB-SAR sensor, the upper part of the plot has been amplified. Since the inclinometric results are given in an horizontal plane, these must be divided by the cosine of the slope angle at $S 10\left(\sim 20^{\circ}\right)$ in order to obtain the total down-slope displacement. Notice how during the period from December 2012 to October 2013, the movement along the maximum-slope according to the inclinometer is $\sim 1.8 \mathrm{~cm} / \cos \left(20^{\circ}\right)=1.91 \mathrm{~cm}$. This corresponds to roughly $\sim 2.3 \mathrm{~cm} /$ year. Results provided by the GB-SAR are $\sim 2.5 \mathrm{~cm} /$ year in this area showing a high agreement with the ground truth provided, and demonstrating again the good performance of GB-SAR sensors for the study of 730 ground displacement monitoring applications.

\section{CONCLUSION}

Urban subsidence and landslide instabilities involve a wide 733 range of issues that are of concern to governments at all lev- 734 els. Increasingly, authorities are promoting actions when they 735 threaten public or private properties and, especially, human 736 life, in order to mitigate the socioeconomic losses derived from 737 these problems.

This paper seeks to demonstrate the usefulness of GB-InSAR 739 and PSI techniques, for the monitoring of different kinds of 740 ground displacement phenomena. With this purpose, two dif- 741 ferent scenarios have been monitored using the RiskSAR sensor 742 and the GB-InSAR processing chain developed by the RSLab 743 [52]. One is an urban area affected by mining induced subsi- 744 dence and the other a mountainous landslide. For both cases, the 745 obtained deformation maps have been validated with in-field 746 ground-truth data. In addition, the key logistics' particularities 747 and processing approach have been deeply analyzed depend- 748 ing on the nature of the area and the ground displacement 749 process to be monitored. Concretely, the APS estimation and 750 compensation step, which represents one of the most criti- 751 cal aspects in GB-InSAR, has been deeply discussed for each 752 scenario.

The reliability of GB-SAR products has been demonstrated, 754 representing an effective alternative for the design and imple- 755 mentation of prevention strategies, showing a high feasibility 756 to hazard assessment and risk management. 757

Compared with PSI spaceborne solutions, GB-SAR sensors 758 present several advantages due to the zero-baseline configura- 759 tion of the instrument, which is firmly anchored on the same 760 position for all acquisitions. The revisiting time is no longer a 761 constraint due to the employment of a terrestrial platform. In 762 addition, they offer the possibility to fit the illumination angle 763 in order to maximize the detection of real ground displace- 764 ment in the LOS direction. Anyway, this is strongly dependent 765 on the characteristics of the site and in some cases it could 766 not be possible. For instance, for urban subsidence monitor- 767 ing not always there will be a nearby cliff. Finally, since 768 APS may be perfectly estimated and compensated for, lower 769 numbers of images are required in order to achieve reliable 770 nonlinear estimations of the ground displacement processes. 771 Compared with traditional in-field monitoring devices and tech- 772 niques, including total stations, differential GPS, geological 773 mapping, geophysical prospection, topographic leveling, exten- 774 someters, inclinometers, and piezometers, GB-SAR solutions 775 have demonstrated to provide higher densities and to be very 776 efficient in order to cover larger areas for long periods at lower 777 cost.

Some future work lines may include the extension of the APS 779 model-based techniques proposed in this paper for the monitor- 780 ing of large-scale scenarios characterized by several kilometers 781 in range. Moreover, the ability to solve unwrapping errors 782 when facing more complex terrains and larger illuminated areas 783 should be deeply analyzed. 


\section{ACKNOWLEDGMENT}

The authors would like to thank Prof. J. Corominas and J. A. Gili from the Department of Geotechnical Engineering and Geosciences, Universitat Politècnica de Catalunya (UPC), their helpful discussions and support in the interpretation of the final displacement results over the test site of El Forn de Canillo. They also wish to thank the Institut Cartogràfic i Geològic de Catalunya (ICGC) for the ground-truth map provided in the test-site of Sallent, and finally, the firm Euroconsult for the inclinometric results for the test-site of El Forn de Canillo.

\section{REFERENCES}

[1] D. Massonnet and K. L. Feigl, "Radar interferometry and its application to changes in the Earth's surface," Rev. Geophys., vol. 36, no. 4, p. 441, 1998.

[2] R. Bürgmann, P. A. Rosen, and E. J. Fielding, "Synthetic aperture radar interferometry to measure Earth's surface topography and its deformation," Апnи. Rev. Earth Planetary Sci., vol. 28, no. 1, pp. 169-209, May 2000.

[3] A. K. Gabriel, R. M. Goldstein, and H. A. Zebker, "Mapping small elevation changes over large areas: Differential radar interferometry," J. Geophys. Res., vol. 94, no. B7, p. 9183, 1989.

[4] A. Ferretti, C. Prati, and F. Rocca, "Nonlinear subsidence rate estimation using permanent scatterers in differential SAR interferometry," IEEE Trans. Geosci. Remote Sens., vol. 38, no. 5, pp. 2202-2212, Sep. 2000.

[5] A. Ferretti, C. Prati, and F. Rocca, "Permanent scatterers in SAR interferometry," IEEE Trans. Geosci. Remote Sens., vol. 39, no. 1, pp. 8-20, Jan. 2001.

[6] O. Mora, J. J. Mallorqui, and J. Duro, "Generation of deformation maps at low resolution using differential interferometric SAR data," in Proc. IEEE Int. Geosci. Remote Sens. Symp., 2002, vol. 5, pp. 2696-2698.

[7] P. Berardino, G. Fornaro, R. Lanari, and E. Sansosti, "A new algorithm for surface deformation monitoring based on small baseline differential SAR interferograms," IEEE Trans. Geosci. Remote Sens., vol. 40, no. 11, pp. 2375-2383, Nov. 2002.

[8] O. Mora, J. Mallorqui, and A. Broquetas, "Linear and nonlinear terrain deformation maps from a reduced set of interferometric SAR images," IEEE Trans. Geosci. Remote Sens., vol. 41, no. 10, pp. 2243-2253, Oct. 2003.

[9] C. Werner, U. Wegmuller, T. Strozzi, and A. Wiesmann, "Interferometric point target analysis for deformation mapping," in Proc. IEEE Int. Geosci. Remote Sens. Symp. (IGARSS'03), 2003, vol. 7, pp. 4362-4364.

[10] A. Arnaud et al., "ASAR ERS interferometric phase continuity," in Proc. IEEE Int. Geosci. Remote Sens. Symp., 2003, vol. 2, pp. 1133-1135.

[11] A. Hooper, "A new method for measuring deformation on volcanoes and other natural terrains using InSAR persistent scatterers," Geophys. Res. Lett., vol. 31, no. 23, p. L23611, 2004.

[12] R. Lanari et al., "A small-baseline approach for investigating deformations on full-resolution differential SAR interferograms," IEEE Trans. Geosci. Remote Sens., vol. 42, no. 7, pp. 1377-1386, Jul. 2004.

[13] A. Hooper, "A multi-temporal InSAR method incorporating both persistent scatterer and small baseline approaches," Geophys. Res. Lett., vol. 35, no. 16, p. L16302, Aug. 2008.

[14] G. Fornaro, D. Reale, and F. Serafino, "Four-dimensional SAR imaging for height estimation and monitoring of single and double scatterers," IEEE Trans. Geosci. Remote Sens., vol. 47, no. 1, pp. 224-237, Jan. 2009.

[15] A. Ferretti et al. "A new algorithm for processing interferometric datastacks: SqueeSAR," IEEE Trans. Geosci. Remote Sens., vol. 49, no. 9, pp. 3460-3470, Sep. 2011.

[16] D. Tarchi et al., "SAR interferometry for structural changes detection: A demonstration test on a DAM," in Proc. IEEE Int. Geosci. Remote Sens. Symp. (IGARSS'99), 1999, vol. 3, pp. 1522-1524.

[17] H. Rudolf, D. Leva, D. Tarchi, and A. Sieber, "A mobile and versatile SAR system," in Proc. IEEE Int. Geosci. Remote Sens. Symp. (IGARSS'99), 1999, vol. 1, pp. 592-594.

[18] D. Leva, G. Nico, D. Tarchi, J. Fortuny-Guasch, and A. Sieber, "Temporal analysis of a landslide by means of a ground-based SAR interferometer," IEEE Trans. Geosci. Remote Sens., vol. 41, no. 4, pp. 745-752, Apr. 2003.
[19] S. Brown, S. Quegan, K. Morrison, J. Bennett, and G. Cookmartin, "High- 855 resolution measurements of scattering in wheat canopies-implications for 856 crop parameter retrieval," IEEE Trans. Geosci. Remote Sens., vol. 41, 857 no. 7, pp. 1602-1610, Jul. 2003.

[20] G. Nico, D. Leva, G. Antonello, and D. Tarchi, "Ground-based SAR interferometry for terain mapping: Theory and sensitivity andysis," IEEE \& Trans. Geosci. Remote Sens., vol. 42, no. 6, pp. 1344-1350, Jun. 2004.

[21] G. Luzi et al., "Ground-based radar interferometry for landslides monitor- 862 ing: atmospheric and instrumental decorrelation sources on experimental 863 data," IEEE Trans. Geosci. Remote Sens., vol. 42, no. 11, pp. 2454-2466, 864 Nov. 2004.

[22] A. Aguasca, A. Broquetas, J. J. Mallorqui, and X. Fabregas, "A solid 866 state L to X-band flexible ground-based SAR system for continuous mon- 867 itoring applications," in Proc. IEEE Int. Geosci. Remote Sens. Symp. 868 (IGARSS'04), 2004, vol. 2, pp. 757-760.

[23] L. Pipia, A. Aguasca, X. Fabregas, and J. Mallorqui, "A polarimet- 870 ric ground-based SAR system: First results at X-band," in Proc. URSI 871 Commiss. F Symp. Microw. Remote Sens. Earth Oceans Ice Atmos., Ispra, 872 Italy, Jul. 2005.

[24] L. Noferini et al., "Permanent scatterers analysis for atmospheric correc- 874 tion in ground-based SAR interferometry," IEEE Trans. Geosci. Remote 875 Sens., vol. 43, no. 7, pp. 1459-1471, Jul. 2005.

[25] M. Pieraccini, G. Luzi, and C. Atzeni, "Ground-based interferometric 877 SAR for terrain elevation mapping," Electron. Lett., vol. 36, no. 16, 878 pp. $1416-1417,2000$

[26] Z.-S. Zhou, W.-M. Boerner, and M. Sato, "Development of a groundbased polarimetric broadband SAR system for noninvasive ground-truth validation in vegetation monitoring," IEEE Trans. Geosci. Remote Sens., vol. 42, no. 9, pp. 1803-1810, Sep. 2004.

27] G. Bernardini, P. Ricci, and F. Coppi, "A ground based microwave 8 interferometer with imaging capabilities for remote measurements of 885 displacements," Geotelematics Fair, 2007.

[28] C. Werner, T. Strozzi, A. Wiesmann, and U. Wegmüller, "GAMMA's 887 portable radar interferometer," Proc. 13th FIG Symp. Deform. Meas. 888 Anal., 2008, pp. 1-10.

[29] L. Pipia, "Polarimetric differential SAR interferometry with ground- 890 based sensors," Ph.D. dissertation, Universitat Politècnica de Catalunya, 891 Barcelona, Spain, 2009.

[30] K. Lukin and A. Mogyla "Monitoring of St. Sophia Cathedral interior 893 using Ka-band ground based noise waveform SAR," in Proc. 6th Radar 894 Conf., (EURAD'09), Rome, Italy, 2009, pp. 215-217.

[31] C. Del Ventisette et al., "Using ground-based radar interferometry during 896 emergency: The case of the A3 motorway (Calabria Region, Italy) threat- 897 ened by a landslide," Natural Hazards Earth Syst. Sci., vol. 11, no. 9, 898 pp. 2483-2495, Sep. 2011.

[32] S. Rodelsperger, A. Coccia, D. Vicente, and A. Meta, "Introduction to 900 the new metasensing ground-based SAR: Technical description and data 901 analysis," in Proc. IEEE Int. Geosci. Remote Sens. Symp., Jul. 2012, 902 pp. 4790-4792.

[33] H. Lee, S. Member J.-H. Lee, S. Member, and K.-E. Kim, "Development 904 of a truck-mounted arc-scanning synthetic aperture radar," IEEE Trans. 905 Geosci. Remote Sens., vol. 52, no. 5, pp. 2773-2779, May 2014.

[34] N. Harries, D. Noon, H. Pritchett, and D. Bates, "Slope stability radar for 907 managing rock fall risks in open cut mines," in Proc. 3rd CANUS Rock 908 Mech. Symp., Toronto, ON, Canada, May 2009, vol. 2009, pp. 1-8.

[35] D. Mecatti et al., "Monitoring open-pit quarries by interferometric radar 910 for safety purposes," in Proc. 7th Eur. Radar Conf., Paris, France, Oct. 911 2010, pp. 37-40.

[36] P. Farina et al. "IBIS-M: An innovative radar for monitoring slopes in 913 open-pit mines," in Proc. Int. Symp. Rock Slope Stabil. Open Pit Mining 914 Civil Eng., Vancouver, BC, Canada, 2011.

[37] P. Farina and N. Coli, "Efficient real time stability monitoring of mine walls : The Çöllolar mine case study," in Proc. Int. Mining Congr. Exhib. Turkey, Antalya, Turkey, 2013, pp. 111-117.

[38] D. Tarchi et al., "On the use of ground-based SAR interferometry 919 for slope failure early warning: The Cortenova rock slide (Italy)," in 920 Landslides, 2005, pp. 337-342.

[39] D. Tarchi, "Monitoring landslide displacements by using ground-based 922 synthetic aperture radar interferometry: Application to the Ruinon land- 923 slide in the Italian Alps," J. Geophys. Res., vol. 108, no. B8, p. 2387, 924 2003.

[40] N. Casagli, F. Catani, C. Del Ventisette, and G. Luzi, "Monitoring, pre- 926 diction, and early warning using ground-based radar interferometry," 927 Landslides, vol. 7, no. 3, pp. 291-301, May 2010.

[41] M. Pieraccini et al., "Remote sensing of building structural displace- 929 ments using a microwave interferometer with imaging capability," NDT \& 930 E Int., vol. 37, no. 7, pp. 545-550, 2004.

\section{6

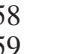 10

76

(1)

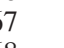

9

$\frac{2}{3}$

\section{3}


[42] L. Pipia et al., "Polarimetric differential SAR interferometry: First results with ground-based measurements," IEEE Geosci. Remote Sens. Lett., vol. 6, no. 1, pp. 167-171, Jan. 2009.

[43] M. Crosetto, O. Monserrat, G. Luzi, M. Cuevas-González, and N. Devanthéry, "Discontinuous GBSAR deformation monitoring," ISPRS J. Photogramm. Remote Sens., vol. 93, pp. 136-141, Jul. 2014.

[44] D. Tarchi, E. Ohlmer, and A. Sieber, "Monitoring of structural changes by radar interferometry," Res. Nondestruct. Eval., vol. 9, no. 4, pp. 213-225, Jan. 1997.

[45] O. Montserrat, "Deformation measurement and monitoring with GroundBased SAR," Ph.D. dissertation, Institute of Geomatics, Barcelona, Spain, 2012.

[46] L. Noferini, D. Mecatti, G. Macaluso, M. Pieraccini, and C. Atzeni, "Monitoring of Belvedere Glacier using a wide angle GB-SAR interferometer," J. Appl. Geophys., vol. 68, no. 2, pp. 289-293, Jun. 2009.

[47] D. Tarchi, "Monitoring landslide displacements by using ground-based synthetic aperture radar interferometry: Application to the Ruinon landslide in the Italian Alps," J. Geophys. Res., vol. 108, no. B8, p. 2387, 2003.

[48] G. Herrera et al., "A landslide forecasting model using ground based SAR data: The Portalet case study," Eng. Geol., vol. 105, no. 3-4, pp. 220-230, May 2009.

[49] G. Barla, F. Antolini, M. Barla, E. Mensi, and G. Piovano, "Monitoring of the Beauregard landslide (Aosta Valley, Italy) using advanced and conventional techniques," Eng. Geol., vol. 116, no. 3-4, pp. 218-235, Nov. 2010.

[50] K. Takahashi, M. Matsumoto, and M. Sato, "Continuous observation of natural-disaster-affected areas using ground-based SAR interferometry," IEEE J. Sel. Topics Appl. Earth Observ. Remote Sens., vol. 6, no. 3, pp. 1286-1294, Jun. 2013.

[51] O. Monserrat, M. Crosetto, and G. Luzi, "A review of ground-based SAR interferometry for deformation measurement," ISPRS J. Photogramm. Remote Sens., vol. 93, pp. 40-48, Jul. 2014.

[52] R. Iglesias et al., "Ground-based polarimetric SAR interferometry for the monitoring of Terrain displacement phenomena. Part I: Theoretical description," to be published.

[53] V. D. Navarro-Sanchez, J. M. Lopez-Sanchez, and L. Ferro-Famil, "Polarimetric approaches for persistent scatterers interferometry," IEEE Trans. Geosci. Remote Sens., vol. 52, no. 3, pp. 1667-1676, Mar. 2014.

[54] R. Iglesias et al., "Phase quality optimization in polarimetric differential SAR interferometry," IEEE Trans. Geosci. Remote Sens., vol. 52, no. 5, pp. 2875-2888, May 2014.

[55] R. Iglesias et al., "Polarimetric optimization of temporal sublook coherence for DInSAR applications," IEEE Geosci. Remote Sens. Lett., vol. 12, no. 1, pp. 87-91, Jan. 2015.

[56] R. Hanssen, Radar Interferometry: Data Interpretation and Error Analysis. Norwell, MA, USA: Kluwer, 2001.

[57] J. Marturià, O. Mora, D. Xifre, P. Martínez, and A. Roca, "DInSAR techniques versus high topographic leveling surveys: The subsidence phenomena in Sallent," in Proc. ECONGEO'06, Barcelona, Spain, 2006.

[58] O. Mora, R. Arbiol, and V. Pala, "ICC's project for DInSAR terrain subsidence monitoring of the Catalonian territory," in Proc. IEEE Int. Geosci. Remote Sens. Symp., 2007, pp. 4953-4956.

[59] L. Pipia, X. Fabregas, A. Aguasca, and C. Lopez-Martinez, "Atmospheric artifact compensation in ground-based DInSAR applications," IEEE Geosci. Remote Sens. Lett., vol. 5, no. 1, pp. 88-92, Jan. 2008.

[60] R. Iglesias, "Atmospheric phase screen compensation in ground-based SAR with a multiple-regression model over mountainous regions," IEEE Trans. Geosci. Remote Sens., vol. 52, no. 5, pp. 2436-2449, May 2014.

[61] L. Pipia, X. Fabregas, A. Aguasca, and C. Lopez-Martinez, "Polarimetric temporal analysis of urban environments with a ground-based SAR," IEEE Trans. Geosci. Remote Sens., vol. 51, no. 4, pp. 2343-2360, Apr. 2013.

[62] R. Touzi, A. Lopes, J. Bruniquel, and P. Vachon, "Coherence estimation for SAR imagery," IEEE Trans. Geosci. Remote Sens., vol. 37, no. 1, pp. 135-149, Jan. 1999.

[63] N. Santacana, "Estudi dels grans esllavissaments d'Andorra: Els casos del Forn i del vessant d'Encampadana." Ph.D. dissertation, Universitat Politècnica de Catalunya (UPC), Barcelona, Spain, 1994.

[64] I. Torrebadella et al., "El Deslizamiento del Forn de Canillo en Andorra. Un Ejemplo de Gestión del Riesgo Geológico en Zonas Habitadas en Grandes Deslizamientos," in Proc. 7th Simposio Nacional sobre Taludes y Laderas Inestables, Barcelona, Spain, 2009, pp. 403-414.

[65] P. Blanco-Sánchez, J. J. Mallorquí, S. Duque, and D. Monells, "The Coherent Pixels Technique (CPT): An advanced DInSAR technique for nonlinear deformation monitoring," Pure Appl. Geophys., vol. 165, no. 6, pp. 1167-1193, Aug. 2008.

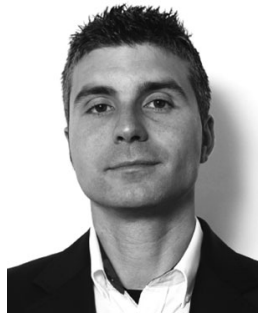

Rubén Iglesias (S'12) was born in Barcelona, Spain, 1009 in 1982. He received the M.Sc. degree in telecommu- 1010 nication engineering from the Universitat Politècnica 1011 de Catalunya (UPC), Barcelona, Spain, in 2008. He 1012 is currently pursuing the Ph.D. degree from UPC, 1013 focused on the development of advanced differen- 1014 tial synthetic aperture radar interferometry (DInSAR) 1015 and polarimetric DInSAR (PolDInSAR) techniques 1016 for the detection, monitoring, and characterization of 1017 slow-moving landslides with both orbital and ground- 1018 based SAR (GB-SAR) data.

1019

From June 2009 to June 2010, he was with the Active Remote Sensing 1020 Unit, Institute of Geomatics, Barcelona, Spain, working in several projects 1021 related with the application of DInSAR to terrain-deformation monitoring with 1022 orbital and GB-SAR data. From June 2010 to March 2014, he was with the 1023 Signal Theory and Communications Department (TSC), UPC, working as a 1024 Research Assistant in the framework of DInSAR and GB-SAR DInSAR appli- 1025 cations. In April 2014, he joined Altamira Information, an experienced Earth 1026 Observation Company in Barcelona dedicated to provide ground displacement 1027 measurements solutions by using DInSAR techniques.

1028

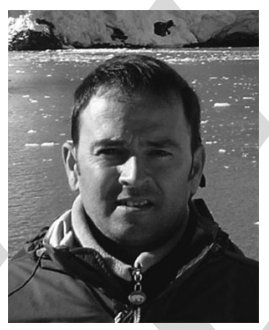

Albert Aguasca (S'90-M'94) was born in 1029 Barcelona, Spain, in 1964. He received the M.Sc. 1030 and $\mathrm{Ph} . \mathrm{D}$. degrees in telecommunication engineering 1031 from the Universitat Politècnica de Catalunya (UPC), 1032 Barcelona, Spain, in 1989 and 1993, respectively. 1033

Since 1995, he has been an Associate Professor 1034 with the School of Telecommunications Engineering, 1035 UPC. His teaching activities involve RF and 1036 microwave circuits for communications and radio 1037 navigation systems. He has published more than 1038 40 papers on microwave synthetic aperture radar, 1039 radiometer systems, and microwave circuits. His research interests include the 1040 design and development of synthetic aperture radar and microwave radiometer 1041 systems for unmanned aerial vehicle (UAV) platforms.

1042

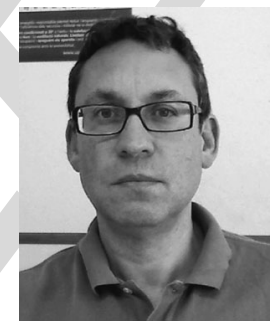

Xavier Fabregas (S'89-M'93) received the B.S. 1043 degree in physics from Barcelona University, 1044 Barcelona, Spain, in 1988, and the Ph.D. degree in 1045 applied sciences from the Universitat Politècnica de 1046 Catalunya (UPC), Barcelona, Spain, in 1995.

In 1990, he joined the Photonic and 1048 Electromagnetic Engineering Group, Signal 1049 Theory and Communications Department, UPC. 1050 Since 1996, he has been an Associate Professor 1051 with the UPC. In 2001, he spent an eight-month 1052 sabbatical with the Microwaves and Radar Institute 1053 (HR), German Aerospace Agency (DLR), Oberpfaffenhofen, Germany. He 1054 has published 26 international journal papers and more than 106 conference 1055 proceedings and has received a patent. He is a Reviewer in several international 1056 journals. His research interests include polarimetric-retrieval algorithms, 1057 polarimetric calibration and speckle models, GB SAR sensors and their 1058 applications, and time series for multidimensional SAR data applications for 1059 urban and terrain deformation monitoring.

1060

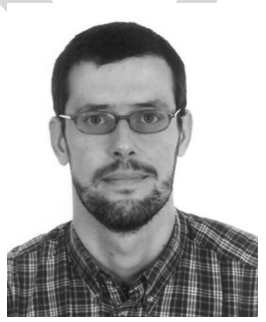

Jordi J. Mallorqui (S'93-M'96-SM'13) was born in 1061 Tarragona, Spain, in 1966. He received the Ingeniero 1062 and Doctor Ingeniero degrees in telecommunica- 1063 tions engineering from the Universitat Politècnica 1064 de Catalunya (UPC), Barcelona, Spain, in 1990 and 1065 1995, respectively. 1066

Since 1993, he has been teaching with the School 1067 of Telecommunications Engineering of Barcelona, 1068 UPC, first as an Assistant Professor, later in 19971069 as an Associate Professor, and since 2011 as a Full 1070 Professor. His teaching activity involves microwaves, 1071 radionavigation systems, and remote sensing. He spent a sabbatical year 1072 with the Jet Propulsion Laboratory, Pasadena, CA, USA, in 1999, working 1073 on interferometric airborne synthetic aperture radar (SAR) calibration algo- 1074 rithms. He is currently working on the application of SAR interferometry to 1075 terrain-deformation monitoring with orbital, airborne, and ground data; ves- 1076 sel detection and classification from SAR images; and 3-D electromagnetic 1077 (EM) simulation of SAR systems. He has published more than 100 papers on 1078 microwave tomography, EM numerical simulation, and SAR processing, inter- 1079 ferometry, and differential interferometry in refereed journals and international 1080 symposia.

1081 


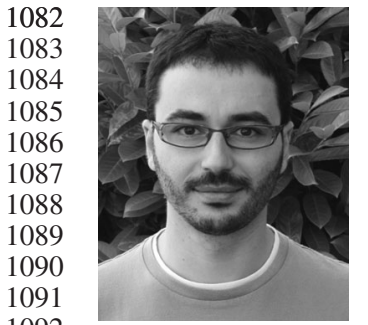

Dani Monells (S'11) was born in Sant Joan de les Abadesses, Spain, in 1981. He received the B.Sc. degree in telecommunication engineering from the Universitat Politècnica de Catalunya (UPC), Barcelona, Spain, in 2008. He is currently pursuing the Ph.D. degree focused on differential synthetic aperture radar interferometry (DInSAR) in orbital platforms, focusing on the exploitation of polarimetric SAR acquisitions (PolSAR), at the Signal Theory and Communications Department (TSC), UPC.

Since 2007, he has been working in several projects for the monitoring of terrain displacements and developing the TSC interferometric chain and processor, in order to give support to the new generation SAR satellites.

1096

1097

1098

1099

1100

1101

1102

1103

1104

1105

1106

1107

1108

1109

1110

1111

1112

1113

1114

1115

1116

1117

1118

1119

1120

1121

1122

1123

1124
From October 2000 to March 2002, he was with the Frequency and Radar Systems Department (HR), German Aerospace Center (DLR), Oberpfaffenhofen, Germany. From June 2003 to December 2005, he has been with the Image and Remote Sensing Group, SAR Polarimetry Holography Interferometry Radargrammetry (SAPHIR) Team, Institute of Electronics and Telecommunications of Rennes (IETR), Rennes, France. In January 2006, he joined the Universitat Politècnica de Catalunya, Barcelona, Spain, as a Ramn-y-Cajal Researcher, where he is currently an Associate Professor in the area of remote sensing and microwave technology. His research interests include SAR and multidimensional SAR, radar polarimetry, physical parameter inversion, digital signal processing, estimation theory, and harmonic analysis.

Dr. López-Martínez is an Associate Editor of the IEEE JouRnAL OF SELECTED TOPICS IN APPlied EARTH ObSERVATIONS AND REMOTE SENSING and he served as Guest Editor of the European Association for Signal Processing (EURASIP) Journal on Advances in Signal Processing. He has organized different invited sessions in international conferences on radar and SAR polarimetry. He has presented advanced courses and seminars on radar polarimetry to a wide range of organizations and events. He received the Student Prize Paper Award at the European Conference on Synthetic Aperture Radar (EUSAR) 2002 Conference and co-authored the paper awarded with the First Place Student Paper Award at the EUSAR 2012 Conference.

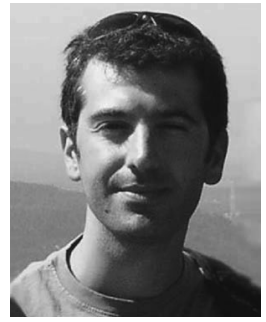

Luca Pipia received the B.S. degree (cum laude) in 1125 electrical engineering from the Università Degli Studi 1126 di Cagliari, Cagliari, Italy, in 2002, and the Ph.D. 1127 degree in polarimetric differential SAR interferome- 1128 try (PolDIInSAR) from the Universitat Politècnica de 1129 Catalunya (UPC), Barcelona, Spain, in 2009.

1130

From June 2001 to December 2001, he was 1131 with the High-Frequency Institute of the German 1132 Aerospace Center (DLR), Oberpfaffenhofen, 1133 Germany, where he worked on land classification 1134 using polarimetric SAR (PolSAR) information. From 1135 2003 to 2009, he was with the Remote Sensing Laboratory, Departament 1136 de Teoria del Senyal i Comunicacions, UPC, where he was deeply involved 1137 in the development and assessment of a novel polarimetric formulation of 1138 coherence-based advanced DinSAR techniques using real ground-based 1139 PolSAR data. Currently, he is with the Remote Sensing Group, Institut 1140 Cartogrfic de Catalunya. His research interests include SAR polarimetry, 1141 differential SAR interferometry, and the retrieval of quantitative information 1142 from hyperspectral visible, near- and thermal-infrared airborne data.

Dr. Pipia has served as a Reviewer for the IEEE JOURNAL OF SELECTED 1144 Topics in Applied Earth ObServations And Remote Sensing, the 1145 IEEE Geoscience And Remote Sensing Letters, and the IEEE 1146 Transactions on Geoscience and Remote Sensing.
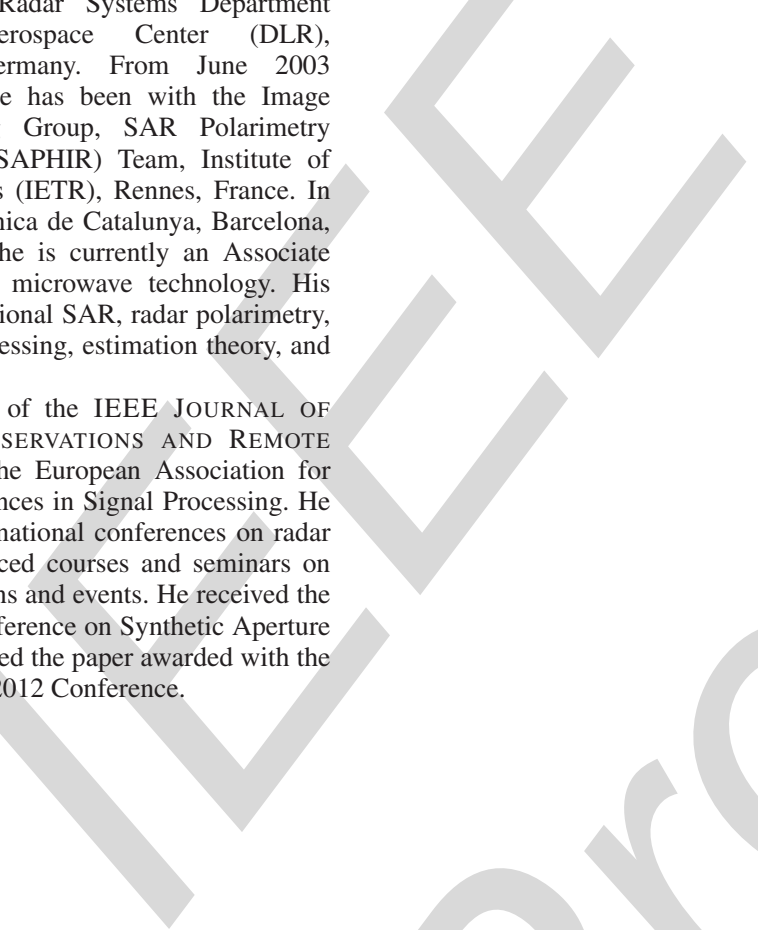


\title{
Ground-Based Polarimetric SAR Interferometry for the Monitoring of Terrain Displacement Phenomena. Part II: Applications
}

\author{
Rubén Iglesias, Student Member, IEEE, Albert Aguasca, Member, IEEE, Xavier Fabregas, Member, IEEE, \\ Jordi J. Mallorqui, Senior Member, IEEE, Dani Monells, Student Member, IEEE, \\ Carlos López-Martínez, Senior Member, IEEE, and Luca Pipia
}

\begin{abstract}
Urban subsidence and landslides are among the greatest hazards for people and infrastructure safety and they require an especial attention to reduce their associated risks. In this framework, ground-based synthetic aperture radar (SAR) interferometry (GB-InSAR) represents a cost-effective solution for the precise monitoring of displacements. This work presents the application of GB-InSAR techniques, particularly with the RiskSAR sensor and its processing chain developed by the Remote Sensing Laboratory (RSLab) of the Universitat Politècnica de Catalunya (UPC), for the monitoring of two different types of ground displacement. An example of urban subsidence monitoring over the village of Sallent, northeastern of Spain, and an example of landslide monitoring in $\mathrm{El} \mathrm{Forn} \mathrm{de} \mathrm{Canillo,} \mathrm{located}$ in the Andorran Pyrenees, are presented. In this framework, the key processing particularities for each case are deeply analyzed and discussed. The linear displacement maps and time series for both scenarios are showed and compared with in-field data. For the study, fully polarimetric data acquired at X-band with a zero-baseline configuration are employed in both scenarios. The displacement results obtained demonstrate the capabilities of GBSAR sensors for the precise monitoring of ground displacement phenomena.
\end{abstract}

Index Terms-Differential synthetic aperture radar (SAR) interferometry (DInSAR), displacement monitoring, groundbased SAR (GB-SAR), frequency modulated continuous wave (FMCW) radar, ground-based SAR interferometry (GBInSAR), persistent scatterer interferometry (PSI), polarimetric SAR interferometry (PolInSAR), steepest linear frequency modulated continuous wave (SLFMCW) radar.

$\mathbf{T}$ HE DEVELOPMENT of differential synthetic aperture radar (SAR) interferometry (DInSAR) algorithms during the last decade has demonstrated their usefulness for the precise monitoring of ground displacement episodes [1], [2] with

Manuscript received March 31, 2014; revised July 22, 2014; accepted September 18, 2014. This work was supported in part by the Big Risk Project (contract number BIA2008-06614), and in part by the Project TEC2011-28201C02-01 funded by the Spanish MICINN and FEDER funds.

R. Iglesias, A. Aguasca, X. Fabegas, J. J. Mallorqui, D. Monells, and C. López-Martínez are with the Department of Signal Theory and Communications, Universitat Politècnica de Catalunya, 08034 Barcelona, Spain (e-mail: ruben.iglesias@tsc.upc.edu; aguasca@tsc.upc.edu; fabregas@tsc.upc.edu; mallorqui@tsc.upc.edu; dmonells@tsc.upc.edu; carlos.lopez@tsc.upc.edu).

L. Pipia is with the Institut Cartogràfic Geològic de Catalunya, 08038 Barcelona, Spain (e-mail: luca.pipia@icc.cat).

Color versions of one or more of the figures in this paper are available online at http://ieeexplore.ieee.org.

Digital Object Identifier 10.1109/JSTARS.2014.2366711 millimetric precisions [3]. Furthermore, DInSAR algorithms have boosted the development of persistent scatterer interferometry (PSI) techniques which allows obtaining not only accurate linear velocity estimations but also time series containing the nonlinear displacement component of affected areas [4]-[15].

In this context, two different kinds of sensors may be considered: orbital/airborne or ground-based. Spaceborne SAR sensors have demonstrated to be extremely successful for studying the evolution of displacement processes, especially, over wide areas. Despite this, when flexibility in terms of revisiting time or sensor orientation toward the scene is required, orbital sensors cannot fulfill the requirements. Airborne sensors represent a more flexible solution but contrarily the data processing becomes more difficult. Furthermore, the monitoring campaigns are generally costly and complex to carry out. For this reason, the research activity of several groups has been recently addressed to the development of terrestrial SAR systems [16], [17]. Flexible, easy to deploy, and cheaper if compared to space- or airborne solutions, Ground-Based SAR (GB-SAR) sensors can be presented as an effective, and sometimes complementary, solution for the precise monitoring of small-scale phenomena [18]-[33].

Due to the capability of GB-SAR sensors to carry out a quasi continuous monitoring, one of their most relevant application corresponds to the slope monitoring of open pit mines, in which such systems potentially work as an Early Warning System (EWS) [34]-[37]. Other relevant applications include slope instability monitoring related to rock-slides [38], [39], [21], volcanoes [40], urban monitoring [41]-[43], structure monitoring [44], [16], dike monitoring [45], glacier monitoring [46], and landslides [43], [45], [47]-[50]. A complete classification of the different GB-SAR applications can be found in [51].

This paper presents the applicability of the RiskSAR GBSAR sensor, developed in the Remote Sensing Laboratory (RSLab) of the Universitat Politècnica de Catalunya (UPC) and widely described in Part I of this paper [52], for the efficient monitoring of ground displacement phenomena.

The RiskSAR sensor [22], [29] is based on the employment of high-rate steepest linear frequency modulated continuous wave (SLFMCW) signals. This type of solution allows performing faster scans compared with vector network analyzer (VNA)-based solutions and, hence, minimize the impact of 
tropospheric disturbances and target instabilities during the scanning time. This radar architecture also favors obtaining reliable polarimetric SAR (PolSAR) measurements with no dramatic increase in the scanning time. In this context, it has been recently demonstrated that polarimetric SAR interferometry (PolInSAR) techniques outperform classical singlepolarization PSI performance [53]-[55].

The applications shown in this work are focused on the GBSAR sensor working in a discontinuous operation mode, which means revisiting the site during different measurement days with a certain temporal span. This can be applied when the deformation process is slow enough and does not require a continuous monitoring. As widely explained in [52], the processing for this configuration mode consists of performing first a temporal averaging of each daily data set. This is referred to as short-term processing (STP) and allows improving the signal-to-noise ratio (SNR) of time-stationary targets, leading to a time-averaged SLC image for each measurement day. In the following step, referred to as long-term processing (LTP), the atmospheric artifacts among the different time-averaged SLC images are compensated for. From all methods available in the literature, the RiskSAR processing chain makes use of model-based solutions to carry out the atmospheric phase screen (APS) compensation. This kind of solution has proven to be very effective since it reaches very good results with no need of extra meteorological data or stable ground control points (GCP). Carrying out a proper APS estimation and compensation process is mandatory in order to obtain reliable displacement map estimations. Once a set of APS-free interferograms are obtained, PSI techniques can be applied to obtain reliable linear and nonlinear estimations of ground displacements. Among all the PSI techniques developed in the last decade, this work focuses on the adaptation of the coherent pixels technique (CPT) to work with zero-baseline data [52].

The linear displacement maps and time series over two very different scenarios, a district affected by subsidence due to the mining activity carried out in the surrounding area during the last century, and an active slow-moving landslide located in a mountainous region, are presented. The main logistics and processing particularities for each case are widely discussed. In both scenarios, the RiskSAR sensor was operated at X-band due to its excellent tradeoff among the high spatial resolution of the SLC images acquired, the possibility to achieve a reliable APS compensation and a fine sensitivity to ground displacements. For this reason, the RiskSAR sensor is referred to as RiskSAR-X hereinafter. The slant-range resolution working at $\mathrm{X}$-band is $1.25 \mathrm{~m}$. The cross-range resolution is on the order of $10 \mathrm{mrad}$, ranging from $0.75 \mathrm{~m}$ at near range up to roughly $5 \mathrm{~m}$ at a far range of $1500 \mathrm{~m}$. In both cases, the processing is benefited from the use of fully polarimetric data.

The paper is organized as follows. Section II refers to GBSAR measurement logistics, with emphasis in the importance of choosing a correct location for the sensor depending on the nature of the scenario and on the ground displacement process characteristics. Sections III and IV present the zero-baseline PSI results in the urban scenario of Sallent and in the landslide of El Forn de Canillo, respectively. The main conclusion and major remarks are given in Section V.

\section{MeAsurement Logistics}

Once a GB-SAR solution is adopted for the monitoring 143 of a certain area, the location of the sensor constitutes a 144 crucial issue in order to maximize the performance of the 145 technique. In addition to be able to cover the whole area of 146 interest, two important aspects must be taken into account: 147 the minimization of the so-called SAR geometrical distortions 148 (foreshortening, layover, or shadowing) to have the regions of 149 interest visible to the radar, and the maximization of the sen- 150 sor sensitivity to deformation, as SAR systems are only able 151 of detecting displacements in the line-of-sight (LOS) direction. 152 The selection of the adequate emplacement helps to maximize 153 the sensitivity of the interferometric phase to the deforma- 154 tion process to monitor, and thus provide the best results 155 possible.

These aspects must be taken into account when planning the 157 measurements and, furthermore, in the final interpretation of 158 the results. This section presents their analysis in order to max- 159 imize the performance of ground-based SAR interferometry 160 (GB-InSAR) techniques depending on the nature and environ- 161 mental conditions of the displacement phenomenon.

\section{A. Minimization of SAR Geometric Distortion Effects}

Regardless of the platform nature, three geometric distor- 164 tions are present in SAR imaging. These are the foreshortening, 165 the layover, and the shadowing [56]. Unlike orbital-based 166 SAR sensors, which are constrained by the orbit geometry, 167 GB-SAR sensors allow fitting the sensor location and orien- 168 tation to the specific characteristics of the area under study. 169 This fact allows to minimize, or at least control, these distortion 170 effects.

Shadowing must be especially taken into account when 172 facing urban monitoring applications. Urbanized areas are typ- 173 ically characterized by having a relatively large number of tall 174 man-made structures, such as buildings. If the location of the 175 sensor is decided without considering its impact, it can lead to 176 a large number of shaded areas in the SAR acquisitions. The 177 location of the instrument at a certain height in order to achieve 178 a top view of the area under study minimizes shadowing impact. 179

Contrarily, landslide areas are typically characterized by 180 having a low numbers of man-made structures. Therefore, shad- 181 owing has less impact in these applications. Despite this, it is 182 important to choose a location which allows overcoming the 183 geographical accidents of the scenario. In these areas, fore- 184 shortening plays a more critical role. The illumination angle 185 must depart from the local slope to avoid as much as possible 186 the compression effect produced by this geometrical distortion. 187 A good strategy consists of locating the instrument at the base 188 of the hillside, some meters away from the slope, in order to 189 illuminate all the area of interest minimizing the shadowing and 190 the foreshortening artifacts.

\section{B. Maximization of the Sensitivity to Deformation}

As stated above, SAR systems only have sensitivity in the 193 LOS direction. Due to its different orientation, the measured 194 
displacements are, in general, not the real ones but a projection of them. Using a vector notation, both can be defined as

$$
\begin{aligned}
\mathbf{V}_{L O S} & =\left|\mathbf{V}_{\mathbf{L O S}}\right| \cdot \widehat{\mathbf{l}}_{\mathbf{L O S}} \\
\mathbf{V}_{G} & =\left|\mathbf{V}_{\mathbf{G}}\right| \cdot \widehat{\mathbf{l}}_{\mathbf{G}}
\end{aligned}
$$

where $\mathbf{V}_{G}$ is the ground displacement vector, this is the real deformation, and $\mathbf{V}_{L O S}$ is the LOS displacement vector, this is the projection. The magnitudes $\left|\mathbf{V}_{\mathbf{L O S}}\right|$ and $\left|\mathbf{V}_{\mathbf{G}}\right|$ are related to the intensity of the displacement, and the unitary vectors $\widehat{l}_{\mathbf{L O S}}$ and $\widehat{\mathrm{l}}_{\mathrm{G}}$ indicate the displacement direction. In fact, the former is only a projection of the latter. Thus, the magnitude of both displacement vectors can be related through a scalar product as follows:

$$
\left|\mathbf{V}_{\mathbf{L O S}}\right|=\left|\mathbf{V}_{\mathbf{G}}\right| \cdot \cos (\alpha)
$$

where

$$
\cos (\alpha)=\widehat{\mathrm{l}}_{\mathbf{L O S}} \cdot \widehat{\mathrm{l}}_{\mathbf{G}}
$$

being $\alpha$ the angle between the unitary vectors.

When the ground displacement is expected to be vertical, as it normally occurs with subsidence phenomena in urban scenarios, $\alpha$ directly becomes the local incidence angle $\theta_{i n c}$. In this context, higher sensor location elevations over the area of interest imply shorter incidence angles and thus a better sensitivity to the ground displacement.

When facing landslide monitoring the problem becomes more complex as the real motion of a particular point has an intrinsic topographic dependence related with its local slope. With no a priori knowledge, the more realistic kinetic model of the displacement direction $\widehat{l}_{\mathbf{G}}$ is based on considering that the surface mostly moves along the steepest gradient of the terrain slope. This information may be derived employing a digital elevation model (DEM) of the area. Then, the angle $\alpha$ is directly obtained through (3).

For the current polar-orbiting SAR satellites, the look direction is close to East or West, for ascending or descending orbits, respectively. For this reason, spaceborne SAR systems are mainly sensitive to movements along slopes facing either East or West and almost insensitive to movements in North or South directions. In this context, GB-SAR sensors present a potential advantage with respect to spaceborne ones since they are not constrained by any orbit geometry. GB-SAR sensors can be placed at an adequate location and fit their orientation for illuminating a specific site according to the geometry of the problem.

A good strategy in landslide monitoring applications consists of locating the instrument at the foot of the hillside, using an illumination angle facing the down-slope direction in order to maximize the displacement detection.

\section{URban Monitoring Study CASE}

Urban monitoring represents one of the most interesting issues and major research topics in the SAR community. Subsidence hazards in urban areas involve from damage in man-made structures to the sudden collapse of entire 241 neighborhoods, thus endangering human lives. Two surveying 242 methods are mainly used for ground deformation monitoring 243 purposes over urban scenarios. These are leveling and global 244 positioning system (GPS). In most cases, the difficulty to cover 245 large areas and the poor densities of measurements provided 246 by these techniques hinder the effective identification and char- 247 acterization of complex deformation episodes. Geotechnical 248 devices such as inclinometers, extensometers, or piezometers 249 present similar drawbacks.

GB-SAR sensors hence represent a useful alternative with 251 respect to the previous surveying techniques. They provide pre- 252 cise estimations of ground displacement phenomena over larger 253 areas with a high density of measures at a lower cost.

This section presents the study case of a linear urban subsi- 255 dence phenomenon produced in a district affected by the former 256 mining activity carried out around the area.

\section{A. Test Site and Data Set}

The test site selected corresponds to a district known as $E l \quad 259$ Barri de l'Estació, located in the village of Sallent, northeastern 260 Spain. Nowadays, there is a subsidence phenomenon induced 261 by the intense mining activity carried out in the area during the 262 second quarter of the last century. This deformation process is 263 the consequence of the exploitation of the Enrique Mine, which 264 was opened from 1932 to 1973 and reached a maximum depth 265 of $260 \mathrm{~m}$.

Unexpectedly, during the intense mining works of 1954, a 267 natural cavity of about $120 \mathrm{~m}$ high and $40 \mathrm{~m}$ wide was found. 268 Some years later, during 1957 and 1962, several floods from the 269 Llobregat River occurred that made difficult to continue with 270 the mine exploitation, and finally leading to the closure of the 271 Enrique Mine in the year 1973.

During the period of abandoning, the mine was filled up with 273 saturated salty water. Some decades after, in 1990s, heavy dam- 274 ages started to be appreciated in several man-made structures 275 built within the affected district of El Barri de l'Estació [see 276 Fig. 1(a)].

As a response to the problem, the administration started a 278 research program to identify, characterize, and model the subsi- 279 dence phenomena observed in the affected area [57]. A multiple 280 set of techniques such as laser topographic leveling, geologi- 281 cal mapping, geophysical prospection, extensometric measure- 282 ments, and drilling was employed to evaluate the risk of the 283 already weakened structures to collapse.

In this framework, the RSLab group, jointly with the Institut 285 Cartogràfic i Geològic de Catalunya (ICGC), started in 2003, 286 the study of this area with PSI techniques using spaceborne 287 acquisitions of the European Remote Sensing (ERS) satellite 288 [58]. A new collaboration between the RSLab and the ICGC 289 started in 2006 to assess the performance of GB-SAR sensors 290 in such scenarios. A 1-year measurement campaign was carried 291 out using the RiskSAR-X sensor [22], [29]. It started in June 292 2006 and finished in March 2007. GB-SAR data were acquired 293 during nine measurement days, as reported in Table I. In each 294 measurement day, several scans were carried out in order to 295 improve the SNR of measures. 


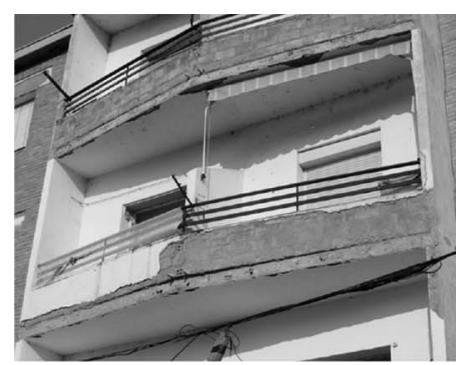

(a)

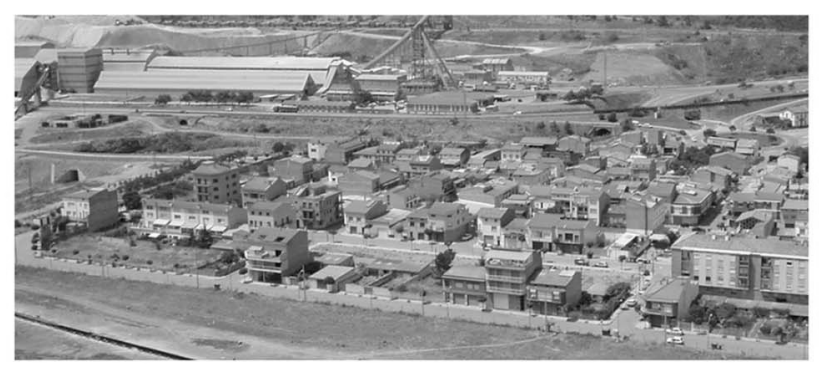

(b)

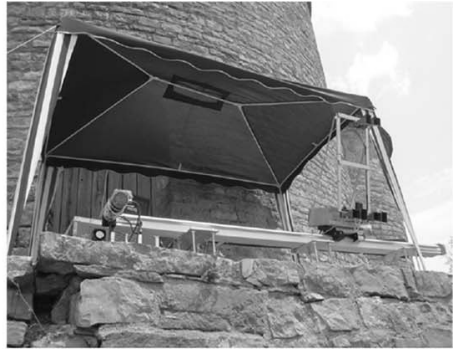

(c)

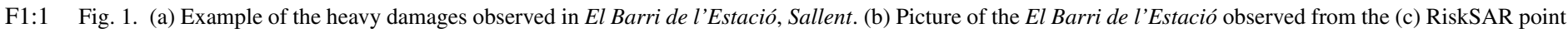
$\mathrm{F} 1: 2$ of view.

$\mathrm{T} 1: 1$

$\mathrm{T} 1: 2$
TABLE I

Timetable of Sallent Measurement Days

\begin{tabular}{ccccc}
\hline Campaign & $\begin{array}{c}\text { Date } \\
\text { dd/mm/yyyy }\end{array}$ & $\begin{array}{c}\text { Start Time } \\
\text { hh:mm }\end{array}$ & $\begin{array}{c}\text { Stop Time } \\
\text { hh:mm }\end{array}$ & Numb. of Scans \\
\hline 1 & $29 / 06 / 2006$ & $11: 00$ & $16: 00$ & 27 \\
2 & $26 / 07 / 2006$ & $08: 00$ & $11: 30$ & 30 \\
3 & $19 / 08 / 2006$ & $10: 40$ & $16: 00$ & 39 \\
4 & $20 / 10 / 2006$ & $09: 40$ & $15: 00$ & 31 \\
5 & $14 / 11 / 2006$ & $12: 30$ & $16: 30$ & 41 \\
6 & $28 / 11 / 2006$ & $19: 00$ & $08: 40$ & 44 \\
7 & $18 / 12 / 2006$ & $20: 45$ & $05: 00$ & 49 \\
8 & $13 / 02 / 2007$ & $22: 00$ & $09: 55$ & 37 \\
9 & $14 / 03 / 2007$ & $20: 00$ & $09: 50$ & 41 \\
\hline
\end{tabular}

\section{B. System Setup}

As seen in Section II, in urban monitoring applications, the GB-SAR location must minimize as far as possible the effects produced by the buildings present in the scenario. This implies to select an emplacement as high as possible in order to have a top view of the area of interest, which minimizes the shadowing and maximizes the sensitivity to vertical displacements.

For these reasons, the instrument was finally installed on the top of a cliff of $84 \mathrm{~m}$ height, $200 \mathrm{~m}$ away in the range direction from the district El Barri de l'Estació. This location provided an incidence angle varying from $72^{\circ}$ up to $82^{\circ}$. It is worth pointing out that installing the radar on the cliff's border prevented the radar front-end of saturations caused by close targets. Moreover, the system was placed on a base at approximately $30 \mathrm{~cm}$ above the ground to raise the rail and reduce the impact of the nearby vegetation.

Another important issue was to ensure a millimetric repositioning of the instrument to avoid a later coregistration of the data. In order to guarantee the repeatability of the observation conditions, the system was mounted over a cement base reinforced with a lightweight metallic frame. A picture of the RiskSAR-X point of view, and the final system setup is detailed in Fig. 1(b) and (c), respectively.

The area of interest illuminated by the RiskSAR sensor extended to approximately $400 \mathrm{~m}$ in range and $300 \mathrm{~m}$ in width. Each scan took roughly $2.5 \mathrm{~min}$ to perform a fully polarimetric measure.

\section{Short-Term and Long-Term Processing}

Prior to the application of the zero-baseline CPT algorithm to 326 obtain PSI results, some important aspects about the STP and 327 LTP [52] processing should be briefly remarked.

As seen, El Barri de l'Estació is an urban area plenty of man- 329 made structures. For this reason, the reflectivity image of the 330 region covered by the sensor has a large dynamic range, with 331 strong reflectivity peaks corresponding to man-made structures, 332 see Fig. 2(a). The coherence in these scenarios remains very 333 high along the temporal axis, as illustrated in Fig. 2(b) and (c), 334 which shows the coherence maps from two acquisitions with 335 a temporal baseline of $15 \mathrm{~min}$ and 23 days, respectively. As 336 shown, the highest coherence pixels are preserved in those areas 337 with higher reflectivity, coinciding with the man-made struc- 338 tures present in the scenario. This fact is of crucial importance, 339 since it will lead to a robust network of temporally coherent 340 scatterers in the later PSI processing.

As it is detailed in [52], in addition to the thermal noise 342 and the temporal decorrelation phenomena, APS represents the 343 most relevant distortion artifact on the interferometric phase. 344 It directly impacts in the STP, which aims to obtain a reliable 345 high-quality time-averaged image from each measurement day. 346 In addition, it also affects the LTP, whose objective is obtain- 347 ing a collection of APS-free interferograms for the later PSI 348 processing. From all the available methods, the RiskSAR sen- 349 sor makes use of model-based solutions [59], [60] since they 350 proved to be very successful with no extra meteorological data 351 or stable GCP.

Fig. 2(d)-(f) shows the interferometric phase evolution due 353 to APS between images separated by temporal spans of $15 \mathrm{~min}, 354$ $1 \mathrm{~h}$, and $4 \mathrm{~h}$, respectively. In such regions, the atmospheric 355 artifacts are smooth in both the spatial and temporal domains. 356 The linear approximation proposed in [59] is sufficient to 357 deal with the APS problematic in these scenarios with soft 358 topography [52].

In order to illustrate the good performance of APS model- 360 based solutions in urban scenarios, the compensation process 361 of an interferogram with a temporal span of $2 \mathrm{~h}$ is presented in 362 Fig. 3. With the goal of generating a reliable vector of observa- 363 tions to carry out the linear regression, only the points with the 364 highest coherence values $(\gamma>0.95)$ are employed. In order to 365 estimate the coherence a $9 \times 9$ multilook is selected. Black dots 366 represent the projection onto the range axis of the interferomet- 367 ric phase. Notice how, as expected, the interferometric phase 368 


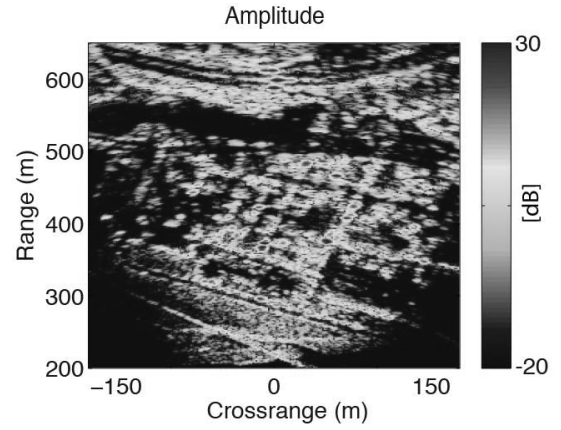

(a)

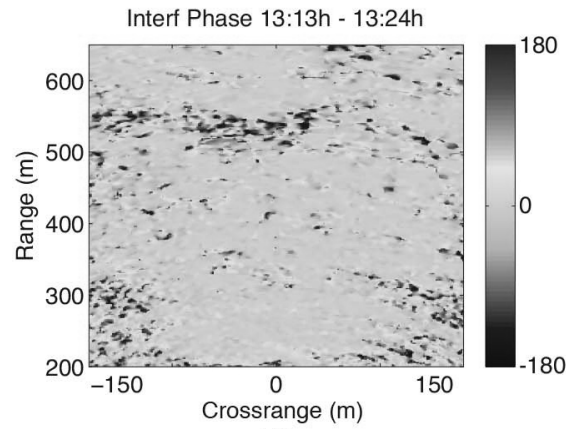

(d)

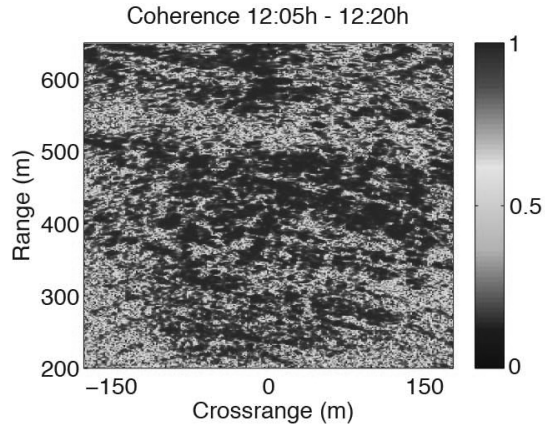

(b)

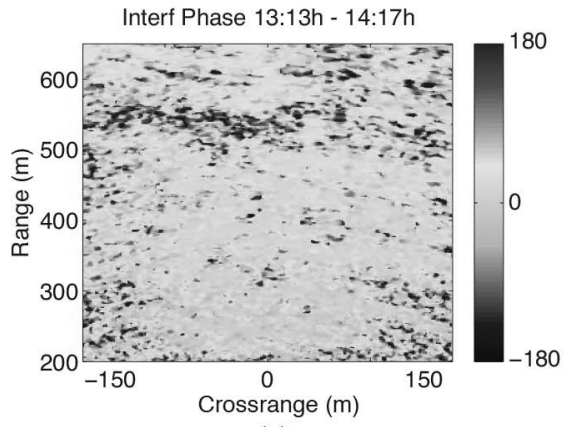

(e)

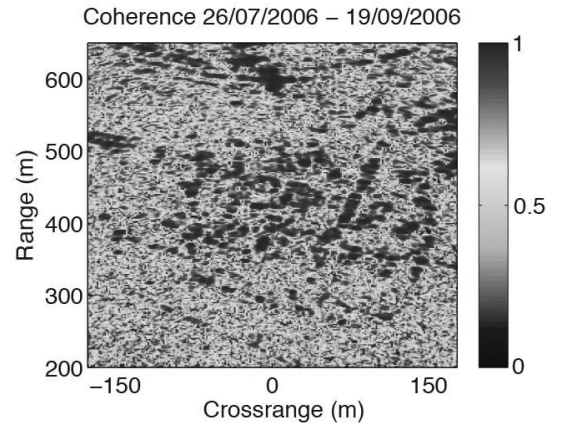

(c)

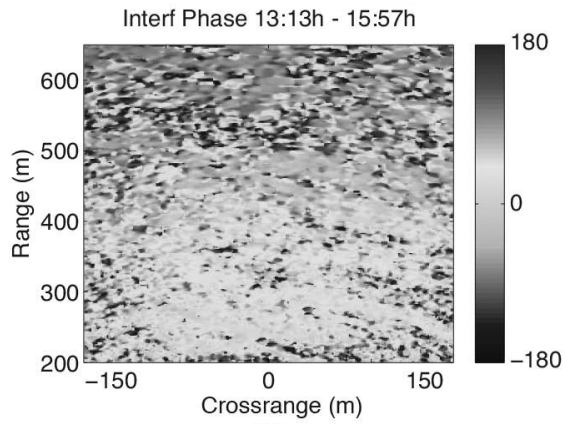

(f)

F2:1 Fig. 2. (a) Reflectivity image in $\mathrm{dB}$ and coherence maps between acquisitions with a temporal baseline of (b) 15 min and (c) 23 days corresponding to the area of F2:2 El Barri de l'Estació, Sallent. Interferometric phase due to the APS between images separated in time (d) 15 min (e) $1 \mathrm{~h}$, and (f) $4 \mathrm{~h}$ approximately.

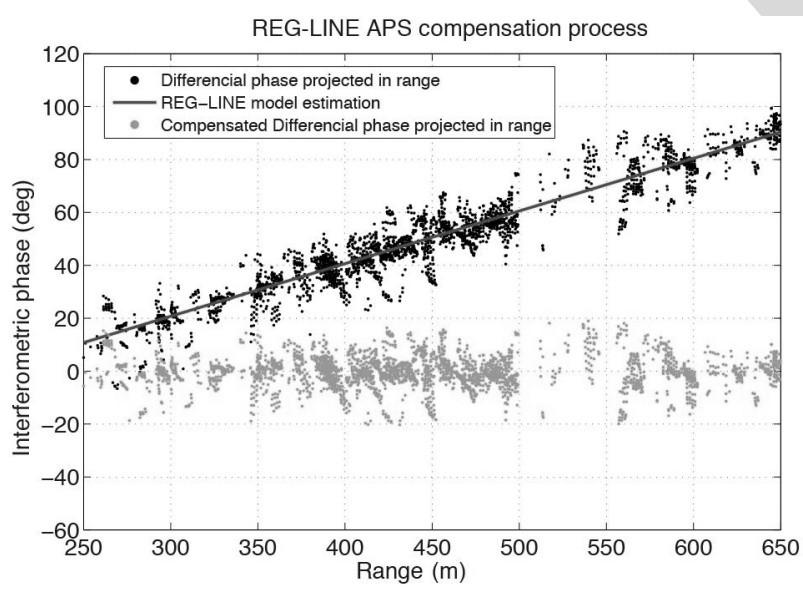

F3:1 Fig. 3. Compensation process of an interferogram with a temporal span of $2 \mathrm{~h}$ F3:2 over those points with a coherence value over 0.95. Black dots represent the F3:3 projection of the interferometric phase onto the range axis. Red line accounts F3:4 for the estimated APS using a linear regression. Green dots correspond to the F3:5 interferometric phase once it has been compensated for. exhibits a strong linear behavior in the range direction. The red line represents the estimated APS using the linear regression method indicated in [52] and [59]. Finally, the green dots correspond to the compensated interferometric phase. Notice how the final interferometric phase has a mean value close to zero. This value is normal since during this short temporal span the interferometric phase may be considered totally independent of any deformation process. In other words, within the same measurement day no detectable movements are expected. Indeed, the interferometric phase of APS-free interferograms has a mean value close to zero.
Due to the large number of high-coherent scatterers available 380 in urban scenarios, the basis-based method explained in [52], 381 which uses a set short-time compensation functions between 382 consecutive daily temporal-averaged images, is not required. 383 Exploiting polarimetry at this point is not necessary for the 384 same reason as well. 385

Finally, in order to reduce the effects of urban target short- 386 time instability induced by human activities, the sample selec- 387 tion technique proposed in [61] is employed for the generation 388 of time-averaged SLC images. The detection of the long-term 389 polarimetric behavior providing the highest number of samples 390 for each day of measurements guaranteed a higher quality of 391 the final interferometric phase information.

\section{Displacement Results}

The displacement map retrieval process is carried out with 394 the zero-baseline adaptation of the CPT algorithm [52]. The 395 choice of the pixel selection method depends on the number 396 of acquisitions at disposal and on the nature of the scatterers to 397 detect, either distributed or point-like scatterers. For this case, 398 since the number of images available is short, only 9, the coher- 399 ence stability criterion has demonstrated to perform well. A 400 threshold of mean coherence corresponding to 0.7, which is 401 equivalent to a phase standard deviation of about $15^{\circ}$, with a 402 $5 \times 5$ multilook window [62], has been established in order to 403 filter out the noisy pixels from the processing. In this type of 404 urban scenarios, a $5 \times 5$ multilook window has demonstrated a 405 good performance to detect man-made structures. 406

At this point, the processing has been benefited by the 407 use of polarimetric optimization techniques [52]. In particular, 408 
the equal scattering mechanism (ESM) polarimetric optimization method [54] has been selected to improve the quality of interferograms. This is translated in roughly a twofold increase in the number of pixels during the pixel selection step.

Finally, the linear velocity map retrieved using the zerobaseline CPT technique is projected over the vertical as indicated in Section II.

The PSI results obtained with the RiskSAR-X sensor are compared with the results provided by the experts of the ICGC [see Fig. 4(a) and (b)], respectively. On the hand, the groundtruth information was obtained by means of a continuous laser topographic levelling system that monitored a set of positions, indicated as dots in Fig. 4(b), during the same period of the GB-SAR campaign. This discrete set of measurements has been employed to obtain the result provided in the same figure through interpolation. On the other hand, due to the high number of high-coherent pixels in the area, GB-SAR results have also been interpolated in order to ease the comparison with the ground-truth available. A high agreement concerning the spatial description of the deformation process may be observed between both techniques. Notice how the position of the area characterized by the maximum deformation bowl perfectly matches. Despite this, it must be pointed out that GB-SAR measurements lead to a slight overestimation of the displacement rate in the center of the deformation focus, $5 \mathrm{~cm} /$ year against the $4.5 \mathrm{~cm} /$ year given by the in situ ground-truth measurements. The difficulty to install the instrument at a higher elevation, to reach shorter incidence angles and maximize the detection in the LOS direction, could explain this slight discrepancy.

Fig. 4(c) shows the time series of a coherent scatter located in the maximum deformation bowl of the area. A strong linearity, as expected from ground-truth measurements and from the spaceborne results available [57], [58], may be observed.

\section{LANDSLIDE Monitoring Study CASE}

Due to the all-weather and day-night capability to accurately detect ground and surface deformations, GB-InSAR has become a useful tool for geo-hazard assessment during the last few years. The accurate monitoring of landslide surfaces represents an important issue in order to achieve a better understanding of landslide mechanisms, and detecting its potential risks to ensure the safety of people living in such areas.

Traditionally, landslide monitoring has been carried out employing different geotechnical devices, including inclinometers, extensometers, piezometers, and GPS differential networks. These in-field measurements present, in general, a benchmark density and a lower extent compared with SAR techniques. In addition, they require the installation of devices directly onto the landslide surface, which can be a problem when the accessibility to the area is complex. The development of remote sensing monitoring tools based on SAR data is becoming an important issue for many authorities in order to ensure the safety of people living in such areas.

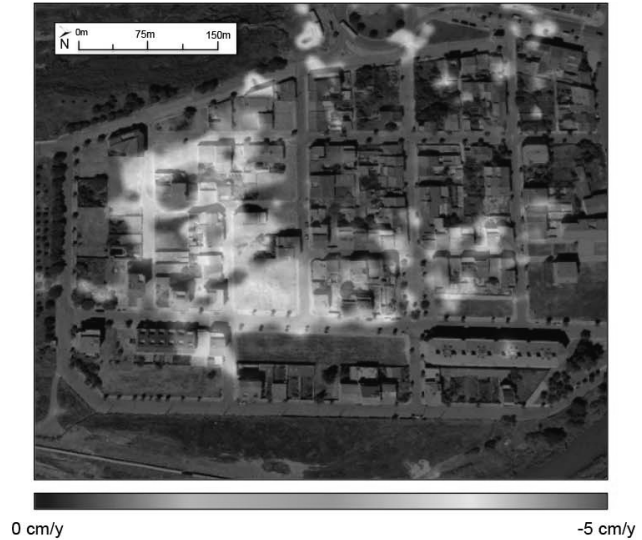

(a)

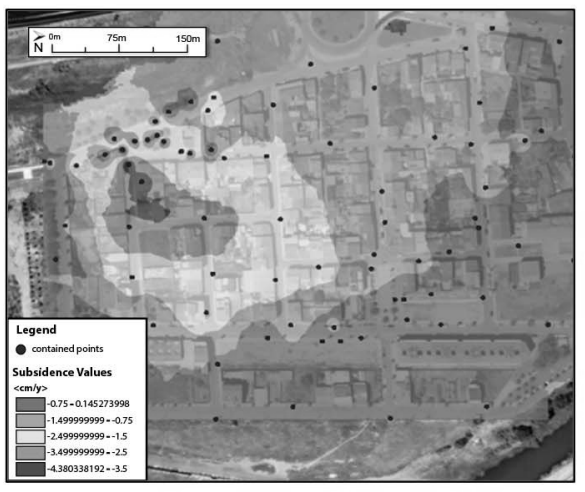

(b)

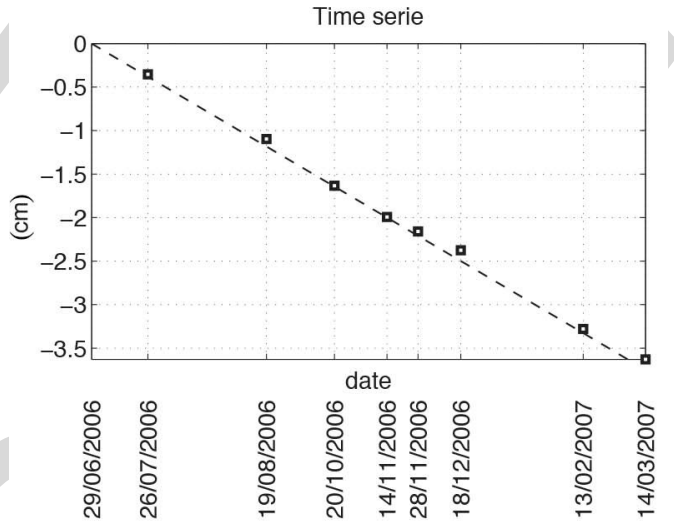

(c)

Fig. 4. (a) Vertical linear displacement map retrieved by using the zero-baseline F4:1 CPT algorithm. (b) Ground-truth map provided by the ICGC employing laser F4:2 topographic leveling techniques. (c) Displacement time series of a point located F4:3 in the center of the deformation focus with a linear velocity of $4.7 \mathrm{~cm} / \mathrm{year} . \quad$ F4:4

\section{A. Test Site and Data Set}

The test site selected to demonstrate the applicability of GB- 466 SAR sensors in these applications corresponds to the landslide 467 of El Forn de Canillo, located in the Andorran Pyrenees. It 468 has been widely studied since 1980s, and today it is consid- 469 ered as one of the largest landslides of the Pyrenean region [see 470 Fig. 5(a)].

The landslide is composed by a sequence of slides and earth- 472 flows with a complex structure, which affects an estimated mass 473 


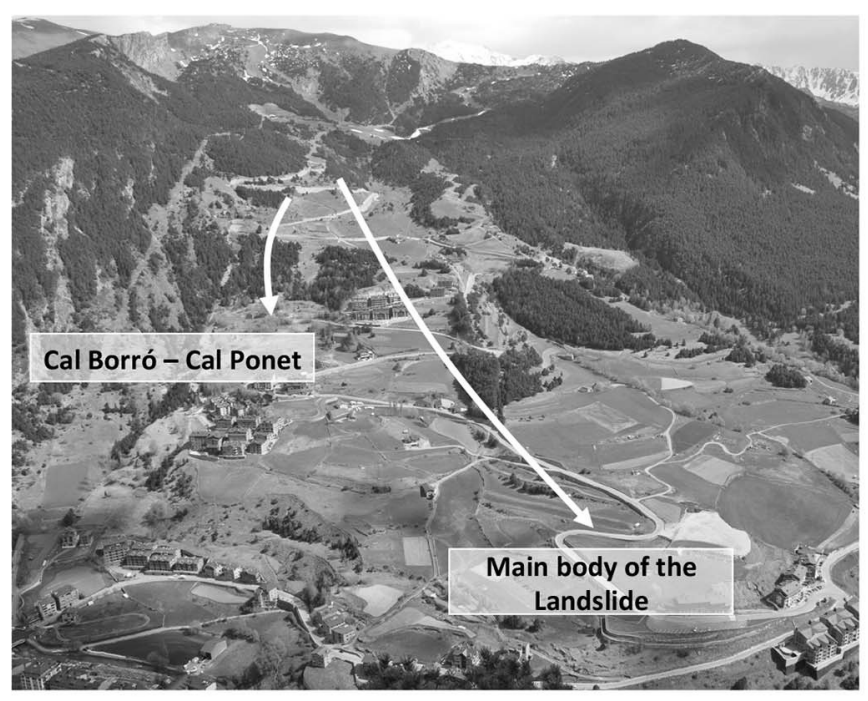

(a)

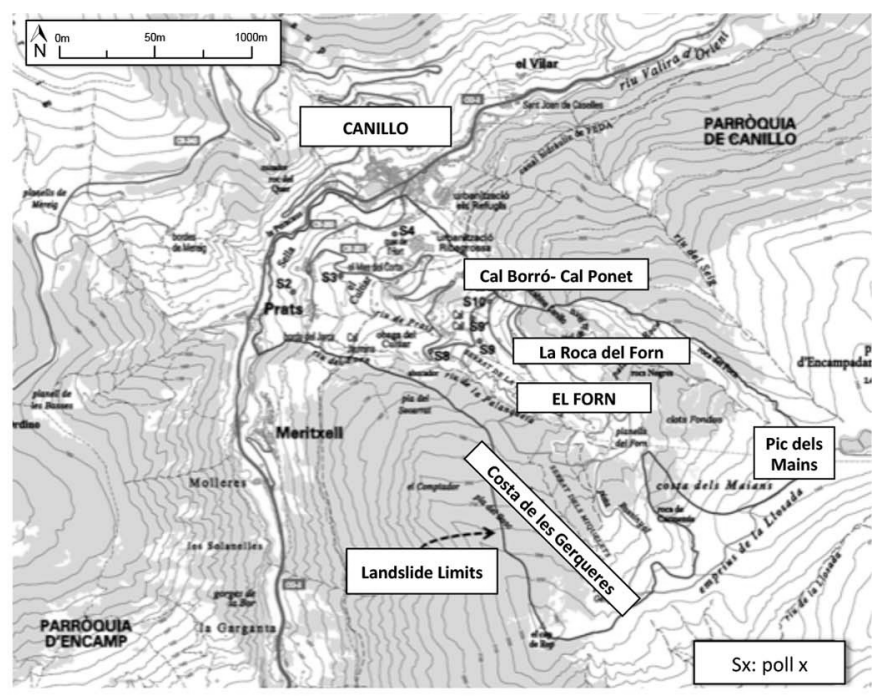

(b)

F5:1 Fig. 5. (a) General overview of the landslide of El Forn de Canillo. (b) Landslide limits and location of the devices installed.

at around $300 \mathrm{Mm}^{3}$. In this context, three major sliding units were identified in 1994 [63]. The first one corresponds to a slide originated in the area of Pla del Géspit-Costa de les Gerqueres [Fig. 5(b)], located in the south-west of the landslide, which reached the foot of the hillside. A second unit was originated under El Pic de Maians [see Fig. 5(b)] reaching a height of $1640 \mathrm{~m}$, and that overlaps with the previous sliding unit, closing in the Valira River valley. Finally, a new rotational slide with a lower extension originated on the hillside known as La Roca del Forn [see Fig. 5(b)] in the north-east side of the hillside has been identified.

The landslide of El Forn de Canillo was originated as the result of the hillside destabilization, due to a decompression phenomenon after the removal of the Valira Glacier, between 13000 and 16000 years before present [63]. The Valira River has been progressively eroding the base of the whole mass without reaching the bedrock, and thus originating the landslide.

The geological observations accumulated during the last decades have evidenced the presence of a main slide mass with a residual movement of some millimeters per year, accompanied by a local failure in the area known as Cal-Ponet Cal-Borró [see Fig. 5(b)] within the third slide unit described above. This slide is presenting today a major activity coinciding with periods of strong rainfalls and snow melting.

In front of all these evidences, the authorities promoted several actions in the year 2000 for the management of the risk related with the geo-hazard threats associated with landslides, rockfalls, and debris flows in the Andorran Pyrenees. Some specific management plans were carried out for the monitoring of El Forn de Canillo.

Between 2007 and 2009, a complex network of geotechnical devices, including inclinometers, rod extensometers, and piezometers, was installed in order to characterize and understand the dynamics of the landslide. A total of 10 boreholes, referred from $S 1$ to $S 10$ in Fig. 5(b), reaching a depth between 40 and $60 \mathrm{~m}$, were drilled and equipped with this instrumentation. The measurements provided by these devices 511 have been recently studied with the objective of locating the 512 sliding surfaces and characterizing the displaced material [64]. 513

Unfortunately, some of the boreholes did not reach the 514 needed depth, and consequently the installed devices did not 515 work properly in some points. Despite this, as it has been 516 expected from in situ observations, the installed devices evi- 517 denced that, in addition to a residual movement of the main lobe 518 of some millimeters per year, the most active part of the land- 519 slide corresponds to the secondary landslide of Cal Borró-Cal 520 Ponet, which between May and June 2009 registered a velocity 521 up to roughly $2 \mathrm{~cm} /$ month [64]. Intense rain events and sudden 522 snow melting was observed during this period. As an example, a 523 famous house built in the mid-19th century, located next to the 524 foot of this secondary landslide near to S10, has experienced 525 a significant damage [see Fig. 6(a)]. Several cracks and shear 526 openings along the road pavements close to this area have also 527 appeared over the last years [see Fig. 6(b)].

In 2011, the use of GB-InSAR techniques to identify and 529 characterize the dynamics of the landslide were planned. The 530 reasons were twofold: on the hand, most of the geotechnical 531 devices implemented did not work properly providing unreli- 532 able measures and, on the other hand, conventional geotechni- 533 cal field measurements present lower densities and thus a worse 534 coverage compared with SAR techniques. For this reason, the 535 RSLab, in collaboration with the Department of Geotechnical 536 Engineering and Geosciences of the UPC, carried out a 1-year 537 measurement campaign, from October 2010 to October 2011, 538 with the objective of identifying and characterizing the behavior 539 of the landslide.

Since the landslide of El Forn de Canillo is nowadays quite 541 stable with some residual movement of the order of few cen- 542 timeters per year, a continuous monitoring was considered 543 clearly unfruitful. For this reason, a total of 10 daily data 544 sets were collected with a temporal base line of approximately 545 1 month, performing thus a discontinuous monitoring, sufficient 546 to avoid phase unwrapping (see Table II). 


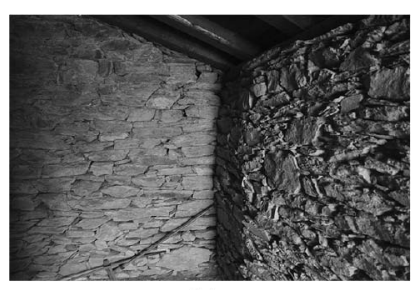

(a)

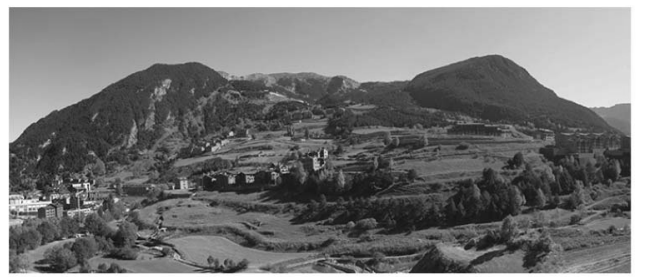

(c)

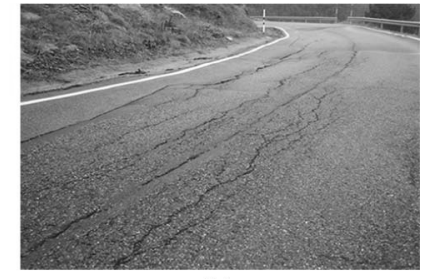

(b)

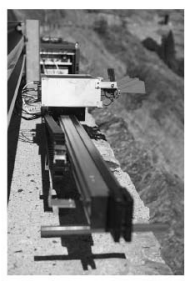

(d)
F6:1

F6:2

F6:3

$\mathrm{F} 6: 4$

F6:5

F6:6

T2:1

T2:2
Fig. 6. (a) Interior view of the cracked walls of a small farmhouse located in the area of Cal Borró-Cal Ponet. The curved shape of the wall indicate the presence of displacements in this area. (b) Cracks and shear openings along a road pavement close to the area of Cal Borró-Cal Ponet. (c) Panoramic view of El Forn de Canillo, in the Andorran Pyrenees from (d) the RiskSAR point of view

TABLE II

Timetable of El Forn de Canillo Measurement Days

\begin{tabular}{ccccc}
\hline Campaign & $\begin{array}{c}\text { Date } \\
\text { dd/mm/yyyy }\end{array}$ & $\begin{array}{c}\text { Start Time } \\
\text { hh:mm }\end{array}$ & $\begin{array}{c}\text { Stop Time } \\
\text { hh:mm }\end{array}$ & Numb. of Scans \\
\hline 1 & $21 / 10 / 2010$ & $09: 57$ & $12: 08$ & 15 \\
2 & $18 / 11 / 2010$ & $17: 04$ & $19: 13$ & 24 \\
3 & $09 / 02 / 2011$ & $17: 00$ & $19: 48$ & 33 \\
4 & $07 / 04 / 2011$ & $18: 17$ & $23: 30$ & 60 \\
5 & $06 / 05 / 2011$ & $10: 02$ & $11: 47$ & 22 \\
6 & $25 / 05 / 2011$ & $16: 09$ & $20: 08$ & 50 \\
7 & $09 / 06 / 2011$ & $13: 20$ & $16: 32$ & 51 \\
8 & $05 / 07 / 2011$ & $08: 25$ & $12: 24$ & 52 \\
9 & $06 / 09 / 2011$ & $11: 49$ & $04: 05$ & 88 \\
10 & $05 / 10 / 2011$ & $11: 57$ & $16: 42$ & 66 \\
\hline
\end{tabular}

\section{B. System Setup}

The RiskSAR-X sensor was located at the foot of the landslide, $100 \mathrm{~m}$ away from the slope, in order to reduce the foreshortening and to maximize the detection of the deformation considering that the landslide moves along the steepest gradient of the terrain slope, as seen in Section II. This emplacement also allows overcoming the geographical accidents of the scenario in order to avoid shadowing in SAR images.

The final area of observation was approximately $500 \mathrm{~m}$ in height, $1600 \mathrm{~m}$ in range, and $1000 \mathrm{~m}$ in width. In addition, as in the urban monitoring case, the system was placed on a base at the height of approximately $30 \mathrm{~cm}$ above the ground, to level the rail and avoid the impact of the nearby vegetation in the measurements. As in the previous study case, each scan took roughly $2.5 \mathrm{~min}$ to perform a fully polarimetric measure.

A picture of the RiskSAR-X point of view and the sensor's location is detailed in Fig. 6(c) and (d), respectively.

\section{Short-Term and Long-Term Processing}

Regarding the characteristics of the scenario, El Forn de 568 Canillo is mainly covered by vegetation and only contains some 569 man-made structures and few rocky areas suitable to perform 570 a reliable GB-InSAR processing. The reflectivity image of the 571 region covered by the RiskSAR-X sensor is shown in Fig. 7(a). 572 Fig. 7(b) and (c) shows the coherence maps of image pairs with 573 a temporal baseline of $13 \mathrm{~min}$ and $6 \mathrm{~h}$, respectively.

Notice how the high-reflectivity areas generally correspond 575 to those pixels with higher coherence values, as expected. These 576 pixels belong to man-made structures, rocky areas, or bare sur- 577 faces. Notice also how coherence decreases faster on vegetated 578 areas at X-band, and how only man-made structures or rocky 579 areas remain coherent along time. A considerable loss of coher- 580 ence in only $6 \mathrm{~h}$ can be noticed. Preserving high-coherent pixels 581 along time is a critical issue in these vegetated scenarios, as seen 582 hereinafter.

As in the urban subsidence study case, some important 584 aspects about the STP and LTP [52] processing must remarked 585 prior applying PSI techniques.

Regarding the APS, contrarily to the study case of urban 587 areas seen above, mountainous regions present severe atmo- 588 spheric phase fluctuations, mainly due to the presence of steep 589 topography. Those regions exhibit strong fluctuations of the 590 atmospheric parameters such as temperature, pressure, and 591 humidity from acquisition to acquisition. Due to this reason, the 592 spatial homogeneity assumption, fulfilled in the previous case, 593 does no longer apply. This fact produces the refractivity index to 594 change in both, the spatial domain, mainly due to the changes 595 in the height, and the temporal one, mainly due to the more 596 extreme atmospheric conditions. The linear-regression model, 597 seen in the urban study case needs to be updated with a second- 598 order term related with the product of range distance and height 599 [52], [60].

In order to illustrate that problem, Fig. 7(d)-(f) is presented. 601 This figure shows the temporal evolution of the interferomet- 602 ric phase after only $1 \mathrm{~h}$. Severe atmospheric phase fluctuations, 603 highly correlated with the steep topography of the scenario, 604 appear in just $1 \mathrm{~h}$ leading to over one-cycle phase variations 605 [see Fig. 7(f)].

Fig. 8 shows how the linear-regression model used in the 607 urban study case is not sufficient to compensate for the APS 608 in these scenarios. The compensation process for this exam- 609 ple is carried out over an interferogram with a temporal span 610 of only $1 \mathrm{~h}$. The black dots represent the projection of the 611 interferometric phase onto the range axis in the pixels of the 612 image with higher coherence values $(\gamma>0.95)$. Notice how 613 the interferometric phase does no longer exhibit a linear behav- 614 ior in the range direction. The red line represents the estimated 615 APS using a linear regression, which considerably departs from 616 the interferometric phase, especially at the near and far range. 617 The blue points refer to the new model, indicated in [52] and 618 [60], which accounts for the height of the scenario. Notice 619 how it perfectly fits the interferometric phase trend. Finally, 620 the green dots correspond to the interferometric phase after the 621 compensation process showing the goodness of the proposed 622 technique. 


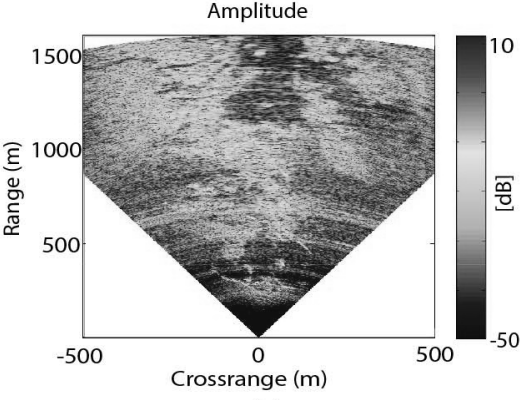

(a)

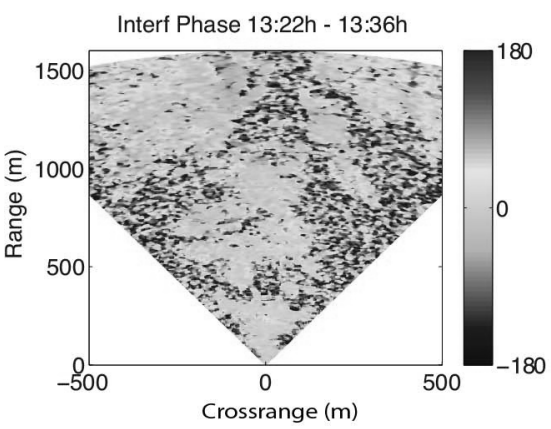

(d)

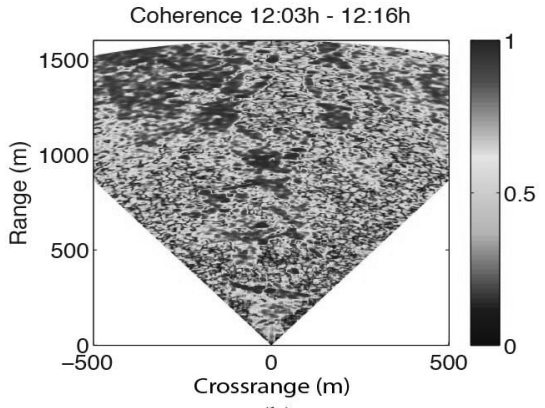

(b)

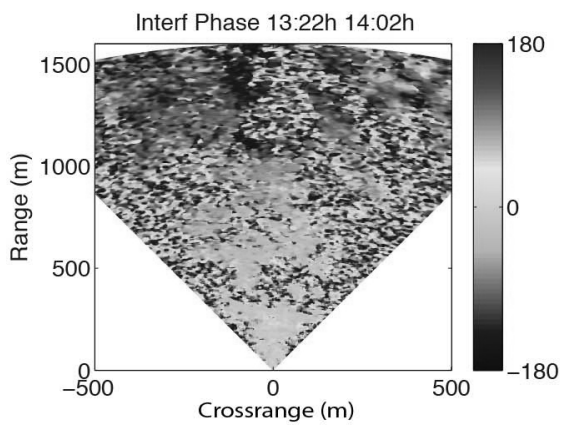

(e)

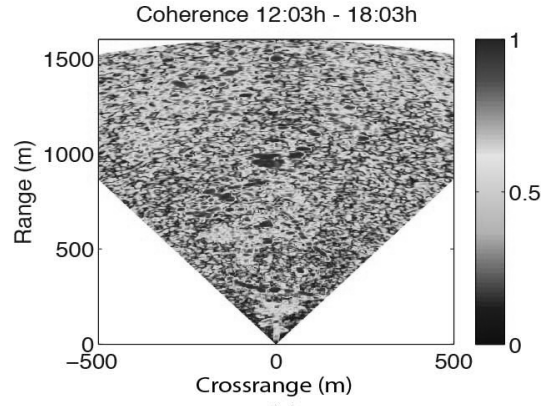

(c)

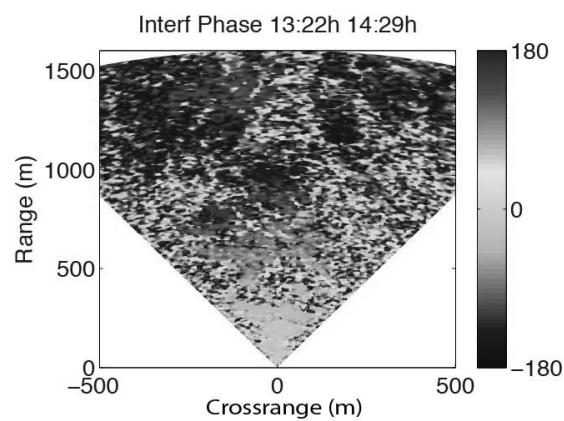

(f)

F7:1 Fig. 7. (a) Reflectivity image in $\mathrm{dB}$ and coherence maps between acquisitions with a temporal baseline of (b) 13 min and (c) $6 \mathrm{~h}$ corresponding to the area of F7:2 El Forn de Canillo, Andorra. Interferometric phase due to APS between images separated in time (d) 15 min (e) $30 \mathrm{~min}$, and (f) $1 \mathrm{~h}$ approximately.

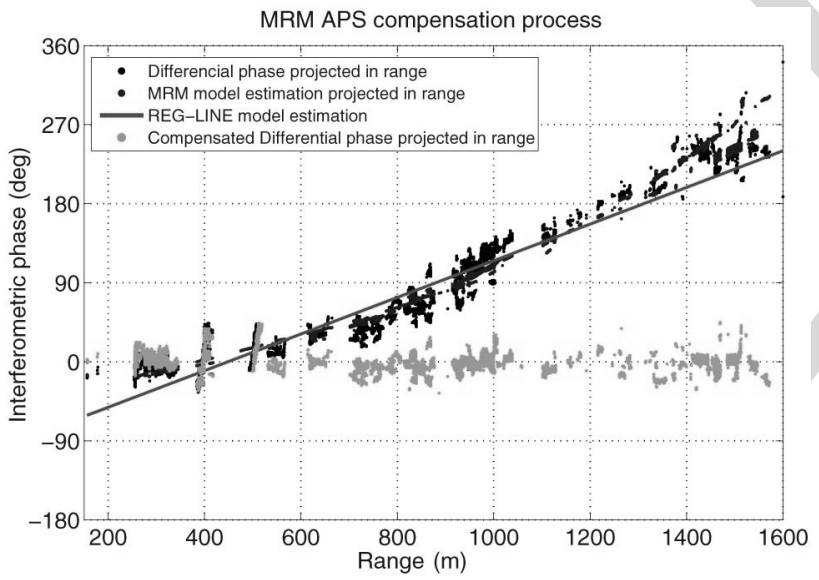

F8:1 Fig. 8. Compensation process of an interferogram with a temporal span of $1 \mathrm{~h}$ F8:2 over those points with a coherence value over 0.95. Black dots represent the F8:3 projection of the interferometric phase onto the range axis. Red line accounts F8:4 for the estimated APS using a linear regression. Blue dots refer to the estimated F8:5 APS using a multiple regression model that takes into account the height of the F8:6 scenario. Green dots correspond to the interferometric phase once it has been F8:7 compensated for.
Fig. 9 illustrates the good performance of the APS compensation technique along time. This figure presents the phase evolution of a coherent scatterer $(\gamma=0.97$ using a $9 \times 9$ multilook) along a total of 70 measures collected during $12 \mathrm{~h}$, from 1:00 P.M. to 1:25 A.M., every $10 \mathrm{~min}$. The dotted line refers to the phase evolution before applying the APS compensation step meanwhile, the solid one accounts for the phase evolution once the APS is compensated. Since all the measures belong to the same measurement day, it is expected an

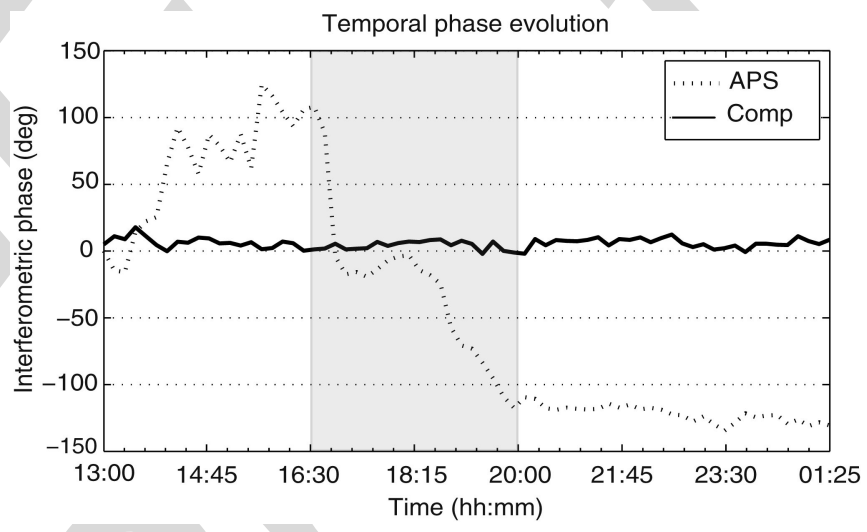

Fig. 9. Phase evolution of a coherent scatterer $(\gamma=0.97$ using a $9 \times 9$ mul- F9: 1 tilook) along 70 measures collected during $12 \mathrm{~h}$, from 1:00 P.M. to 1:25 A.M., F9:2 every $10 \mathrm{~min}$. The dotted line refers to the phase evolution before applying the F9:3 APS compensation step. The solid line accounts for the phase evolution once F9:4 the APS is compensated for. The shaded area accounts for the sunset period, F9:5 coinciding with the more severe APS fluctuations.

F9:6

absence of movement. After performing the APS compensation 633 step, the interferometric phase (solid line) presents a zero-mean 634 value with a low standard deviation value, $\sigma=3.6^{\circ}$, which 635 corresponds to $0.16 \mathrm{~mm}$. This experiment demonstrates the 636 good performance of the technique over these kind of scenar- 637 ios. Fig. 9 also illustrates how the atmosphere fluctuations are 638 more severe during the day, and especially at sunset (shaded 639 area). This fact confirms that the best GB-SAR performances 640 may be achieved measuring at night, especially in these type of 641 mountainous environments. 


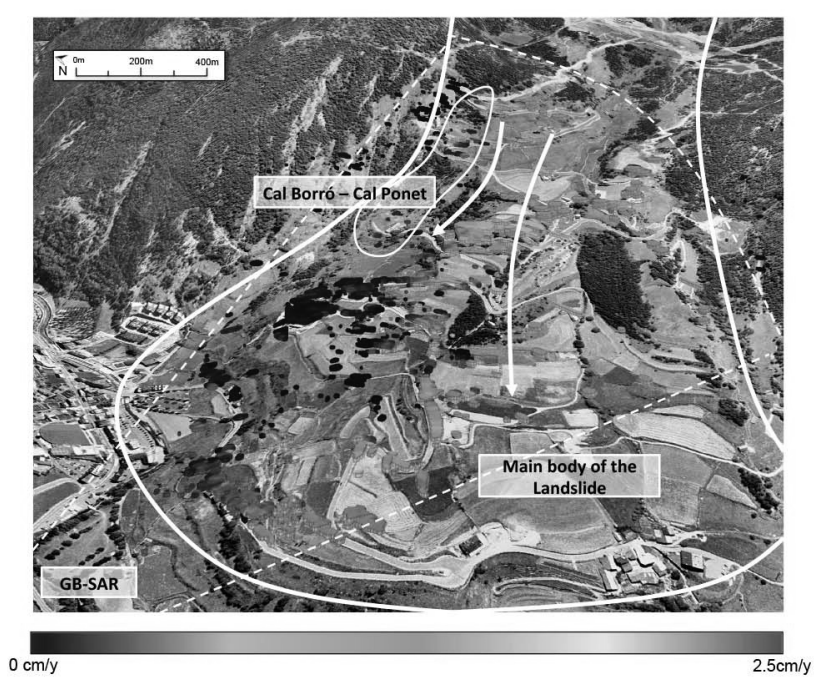

(a)

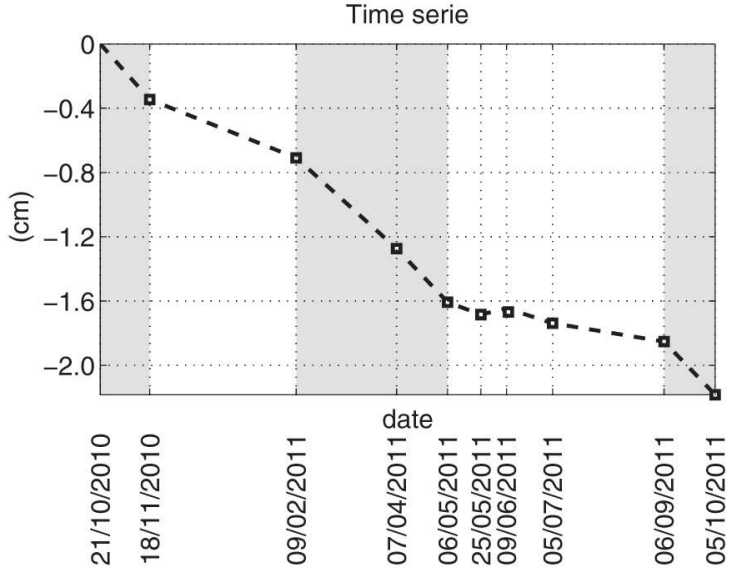

(b)

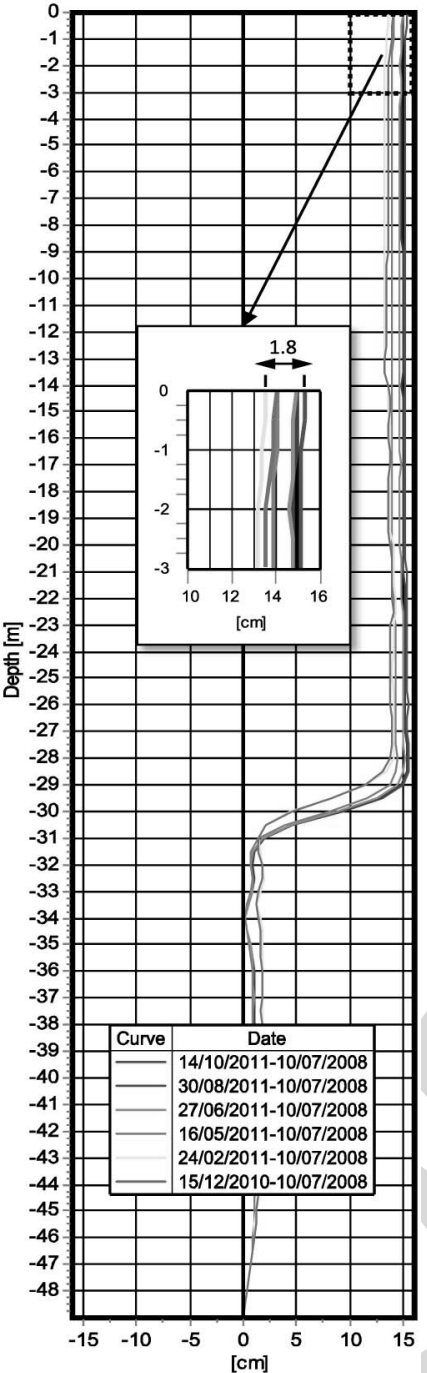

(c)

F10:1 Fig. 10. (a) Geocoded down-slope linear ground-displacement of El Forn de Canillo obtained with the RiskSAR-X sensor covering the period from October 2010 F10:2 to October 2011. (b) Displacement time series of a point located in the area of Cal Borró-Cal Ponet with a linear velocity of $\sim 2.3 \mathrm{~cm} /$ year. The shaded areas indicate the periods when the landslide experienced major accelerations. (c) Inclinometric results provided by the firm Euroconsult in the borehole S10, located in the area of Cal Borró-Cal Ponet.

At this stage, maximizing the chances of detecting the major number of coherent scatterers available within the area of study is mandatory.

On the one hand, the LTP has been benefited from the use of the compensating function method described in [52]. This method seeks to perform the APS estimation and compensation process using the shortest temporal baselines available in the data set. A basis of short-term compensation functions between consecutive daily temporal-averaged images, characterized by a minimum loss of coherence are first generated. Then, these are employed to compensate for long-term span interferograms.

On the other hand, the LTP may also be benefited from the use of PolSAR data [52], [60]. A simple strategy, which notably increases the number of coherent scatters selected, consists of selecting for each interferogram which needs to be compensated for, the polarimetric channel providing the highest coherence value. This strategy leads to a twofold increase in the 659 number of high-quality pixels during APS compensation step. 660

\section{Displacement Results}

The displacement map retrieval is carried out with the zerobaseline adaptation of the CPT technique [52].

Since the number of images available is short, 10 images, the 664 coherence stability criterion is proposed to carry out the pixel 665 selection. This approach performs well even when a reduced 666 number of images are available. Moreover, this pixel selec- 667 tion criterion has demonstrated to be more suited in natural 668 environments with predominance of distributed scatters. $\quad 669$

At this point, since the number of high-quality pixels is 670 smaller for this environment, the zero-baseline CPT algo- 671 rithm is benefited by the use of a multilayer processing [65]. 672 
Two thresholds of mean coherence corresponding to 0.7 and 0.6 are fixed. These correspond to phase standard deviations of about $15^{\circ}$ and $20^{\circ}$, respectively, using a $5 \times 5$ multilook window [62]. This multilook window maximizes the detection of stable coherent scatters coming from both man-made structures and natural targets, such as rocky areas or bare surfaces.

Furthermore, the ESM polarimetric optimization method [54] has also been employed in order to improve the phase quality of interferograms, and thus achieve a dense network of coherent scatterers to carry out a reliable PSI processing.

Fig. 10(a) shows the final down-slope linear grounddisplacement map geocoded over a Google Earth image, using the zero-baseline CPT algorithm. The result shows a high agreement with the conclusions extracted from the field monitoring campaigns made between 2007 and 2009, presented in [64]. Concretely, the displacement map obtained reveals that the main body of the landslide experienced a residual movement of approximately $1 \mathrm{~cm} /$ month during the period of observation. In the top-left, part of the hillside a local landslide presenting a higher activity $(\sim 2-2.5 \mathrm{~cm} /$ year $)$ may be appreciated. It corresponds to the so-called secondary landslide of Cal BorróCal Ponet, described previously. Fig. 10(b) shows the temporal evolution of a high-coherence point belonging to the maximum displacement rate area. Unlike the urban subsidence case studied previously, which was characterized by a strong linear component, the temporal evolution of the displacement has now a strong nonlinear component. It presents several accelerations and stabilizations during the period of measures. The shaded areas in the figure indicate the periods when the landslide experienced major accelerations. Analyzing the figure in detail, it can be observed that the major displacements are produced in the fall (from October to November 2010) and spring (from February to June 2011), coinciding with the major rainfall and snow melting events. In the last period of the graph (September 2011), coinciding again with autumn's arrival, the landslide seems to accelerate again.

Finally, Fig. 10(c) shows the inclinometric results provided by the firm Euroconsult in the borehole $S 10$, located in the maximum deformation rate area of Cal Borr-Cal Ponet. The figure illustrates a horizontal profile of the deformed shape of the inclinometer casing along the borehole depth in the down-slope direction for different dates. The curves correspond to the period corresponding from December 2010 to October 2011, and all are referred to July 2008. The S-shaped plot reflects that the main shear band is located about $30 \mathrm{~m}$ under the surface of the landslide. In order to ease the comparison of the inclinometric results with the ones obtained with the GB-SAR sensor, the upper part of the plot has been amplified. Since the inclinometric results are given in an horizontal plane, these must be divided by the cosine of the slope angle at $S 10\left(\sim 20^{\circ}\right)$ in order to obtain the total down-slope displacement. Notice how during the period from December 2012 to October 2013, the movement along the maximum-slope according to the inclinometer is $\sim 1.8 \mathrm{~cm} / \cos \left(20^{\circ}\right)=1.91 \mathrm{~cm}$. This corresponds to roughly $\sim 2.3 \mathrm{~cm} /$ year. Results provided by the GB-SAR are $\sim 2.5 \mathrm{~cm} /$ year in this area showing a high agreement with the ground truth provided, and demonstrating again the good performance of GB-SAR sensors for the study of 730 ground displacement monitoring applications.

\section{CONCLUSION}

Urban subsidence and landslide instabilities involve a wide 733 range of issues that are of concern to governments at all lev- 734 els. Increasingly, authorities are promoting actions when they 735 threaten public or private properties and, especially, human 736 life, in order to mitigate the socioeconomic losses derived from 737 these problems.

This paper seeks to demonstrate the usefulness of GB-InSAR 739 and PSI techniques, for the monitoring of different kinds of 740 ground displacement phenomena. With this purpose, two dif- 741 ferent scenarios have been monitored using the RiskSAR sensor 742 and the GB-InSAR processing chain developed by the RSLab 743 [52]. One is an urban area affected by mining induced subsi- 744 dence and the other a mountainous landslide. For both cases, the 745 obtained deformation maps have been validated with in-field 746 ground-truth data. In addition, the key logistics' particularities 747 and processing approach have been deeply analyzed depend- 748 ing on the nature of the area and the ground displacement 749 process to be monitored. Concretely, the APS estimation and 750 compensation step, which represents one of the most criti- 751 cal aspects in GB-InSAR, has been deeply discussed for each 752 scenario.

The reliability of GB-SAR products has been demonstrated, 754 representing an effective alternative for the design and imple- 755 mentation of prevention strategies, showing a high feasibility 756 to hazard assessment and risk management. 757

Compared with PSI spaceborne solutions, GB-SAR sensors 758 present several advantages due to the zero-baseline configura- 759 tion of the instrument, which is firmly anchored on the same 760 position for all acquisitions. The revisiting time is no longer a 761 constraint due to the employment of a terrestrial platform. In 762 addition, they offer the possibility to fit the illumination angle 763 in order to maximize the detection of real ground displace- 764 ment in the LOS direction. Anyway, this is strongly dependent 765 on the characteristics of the site and in some cases it could 766 not be possible. For instance, for urban subsidence monitor- 767 ing not always there will be a nearby cliff. Finally, since 768 APS may be perfectly estimated and compensated for, lower 769 numbers of images are required in order to achieve reliable 770 nonlinear estimations of the ground displacement processes. 771 Compared with traditional in-field monitoring devices and tech- 772 niques, including total stations, differential GPS, geological 773 mapping, geophysical prospection, topographic leveling, exten- 774 someters, inclinometers, and piezometers, GB-SAR solutions 775 have demonstrated to provide higher densities and to be very 776 efficient in order to cover larger areas for long periods at lower 777 cost.

Some future work lines may include the extension of the APS 779 model-based techniques proposed in this paper for the monitor- 780 ing of large-scale scenarios characterized by several kilometers 781 in range. Moreover, the ability to solve unwrapping errors 782 when facing more complex terrains and larger illuminated areas 783 should be deeply analyzed. 


\section{ACKNOWLEDGMENT}

The authors would like to thank Prof. J. Corominas and J. A. Gili from the Department of Geotechnical Engineering and Geosciences, Universitat Politècnica de Catalunya (UPC), their helpful discussions and support in the interpretation of the final displacement results over the test site of El Forn de Canillo. They also wish to thank the Institut Cartogràfic i Geològic de Catalunya (ICGC) for the ground-truth map provided in the test-site of Sallent, and finally, the firm Euroconsult for the inclinometric results for the test-site of El Forn de Canillo.

\section{REFERENCES}

[1] D. Massonnet and K. L. Feigl, "Radar interferometry and its application to changes in the Earth's surface," Rev. Geophys., vol. 36, no. 4, p. 441, 1998.

[2] R. Bürgmann, P. A. Rosen, and E. J. Fielding, "Synthetic aperture radar interferometry to measure Earth's surface topography and its deformation," Аnnu. Rev. Earth Planetary Sci., vol. 28, no. 1, pp. 169-209, May 2000.

[3] A. K. Gabriel, R. M. Goldstein, and H. A. Zebker, "Mapping small elevation changes over large areas: Differential radar interferometry," J. Geophys. Res., vol. 94, no. B7, p. 9183, 1989.

[4] A. Ferretti, C. Prati, and F. Rocca, "Nonlinear subsidence rate estimation using permanent scatterers in differential SAR interferometry," IEEE Trans. Geosci. Remote Sens., vol. 38, no. 5, pp. 2202-2212, Sep. 2000.

[5] A. Ferretti, C. Prati, and F. Rocca, "Permanent scatterers in SAR interferometry," IEEE Trans. Geosci. Remote Sens., vol. 39, no. 1, pp. 8-20, Jan. 2001.

[6] O. Mora, J. J. Mallorqui, and J. Duro, "Generation of deformation maps at low resolution using differential interferometric SAR data," in Proc. IEEE Int. Geosci. Remote Sens. Symp., 2002, vol. 5, pp. 2696-2698.

[7] P. Berardino, G. Fornaro, R. Lanari, and E. Sansosti, "A new algorithm for surface deformation monitoring based on small baseline differential SAR interferograms," IEEE Trans. Geosci. Remote Sens., vol. 40, no. 11, pp. 2375-2383, Nov. 2002.

[8] O. Mora, J. Mallorqui, and A. Broquetas, "Linear and nonlinear terrain deformation maps from a reduced set of interferometric SAR images," IEEE Trans. Geosci. Remote Sens., vol. 41, no. 10, pp. 2243-2253, Oct. 2003.

[9] C. Werner, U. Wegmuller, T. Strozzi, and A. Wiesmann, "Interferometric point target analysis for deformation mapping," in Proc. IEEE Int. Geosci. Remote Sens. Symp. (IGARSS'03), 2003, vol. 7, pp. 4362-4364.

[10] A. Arnaud et al., "ASAR ERS interferometric phase continuity," in Proc. IEEE Int. Geosci. Remote Sens. Symp., 2003, vol. 2, pp. 1133-1135.

[11] A. Hooper, "A new method for measuring deformation on volcanoes and other natural terrains using InSAR persistent scatterers," Geophys. Res. Lett., vol. 31, no. 23, p. L23611, 2004.

[12] R. Lanari et al., "A small-baseline approach for investigating deformations on full-resolution differential SAR interferograms," IEEE Trans. Geosci. Remote Sens., vol. 42, no. 7, pp. 1377-1386, Jul. 2004.

[13] A. Hooper, "A multi-temporal InSAR method incorporating both persistent scatterer and small baseline approaches," Geophys. Res. Lett., vol. 35, no. 16, p. L16302, Aug. 2008.

[14] G. Fornaro, D. Reale, and F. Serafino, "Four-dimensional SAR imaging for height estimation and monitoring of single and double scatterers," IEEE Trans. Geosci. Remote Sens., vol. 47, no. 1, pp. 224-237, Jan. 2009.

[15] A. Ferretti et al., "A new algorithm for processing interferometric datastacks: SqueeSAR," IEEE Trans. Geosci. Remote Sens., vol. 49, no. 9, pp. 3460-3470, Sep. 2011.

[16] D. Tarchi et al., "SAR interferometry for structural changes detection: A demonstration test on a DAM," in Proc. IEEE Int. Geosci. Remote Sens. Symp. (IGARSS'99), 1999, vol. 3, pp. 1522-1524.

[17] H. Rudolf, D. Leva, D. Tarchi, and A. Sieber, "A mobile and versatile SAR system," in Proc. IEEE Int. Geosci. Remote Sens. Symp. (IGARSS'99), 1999, vol. 1, pp. 592-594.

[18] D. Leva, G. Nico, D. Tarchi, J. Fortuny-Guasch, and A. Sieber, "Temporal analysis of a landslide by means of a ground-based SAR interferometer," IEEE Trans. Geosci. Remote Sens., vol. 41, no. 4, pp. 745-752, Apr. 2003.
[19] S. Brown, S. Quegan, K. Morrison, J. Bennett, and G. Cookmartin, "High- 855 resolution measurements of scattering in wheat canopies-implications for 856 crop parameter retrieval," IEEE Trans. Geosci. Remote Sens., vol. 41, 857 no. 7, pp. 1602-1610, Jul. 2003.

[20] G. Nico, D. Leva, G. Antonello, and D. Tarchi, "Ground-based SAR interferometry for terain mapping: Theory and sensitivity andysis," IEEE 8 Trans. Geosci. Remote Sens., vol. 42, no. 6, pp. 1344-1350, Jun. 2004. 861

[21] G. Luzi et al., "Ground-based radar interferometry for landslides monitor- 862 ing: atmospheric and instrumental decorrelation sources on experimental 863 data," IEEE Trans. Geosci. Remote Sens., vol. 42, no. 11, pp. 2454-2466, 864 Nov. 2004.

[22] A. Aguasca, A. Broquetas, J. J. Mallorqui, and X. Fabregas, "A solid 866 state L to X-band flexible ground-based SAR system for continuous mon- 867 itoring applications," in Proc. IEEE Int. Geosci. Remote Sens. Symp. 868 (IGARSS'04), 2004, vol. 2, pp. 757-760.

[23] L. Pipia, A. Aguasca, X. Fabregas, and J. Mallorqui, "A polarimet- 870 ric ground-based SAR system: First results at X-band," in Proc. URSI 871 Commiss. F Symp. Microw. Remote Sens. Earth Oceans Ice Atmos., Ispra, 872 Italy, Jul. 2005.

[24] L. Noferini et al., "Permanent scatterers analysis for atmospheric correc- 874 tion in ground-based SAR interferometry," IEEE Trans. Geosci. Remote 875 Sens., vol. 43, no. 7, pp. 1459-1471, Jul. 2005.

[25] M. Pieraccini, G. Luzi, and C. Atzeni, "Ground-based interferometric 877 SAR for terrain elevation mapping," Electron. Lett., vol. 36, no. 16, 878 pp. $1416-1417,2000$

[26] Z.-S. Zhou, W.-M. Boerner, and M. Sato, "Development of a groundbased polarimetric broadband SAR system for noninvasive ground-truth validation in vegetation monitoring," IEEE Trans. Geosci. Remote Sens., vol. 42, no. 9, pp. 1803-1810, Sep. 2004.

27] G. Bernardini, P. Ricci, and F. Coppi, "A ground based microwave 8 interferometer with imaging capabilities for remote measurements of 885 displacements," Geotelematics Fair, 2007.

[28] C. Werner, T. Strozzi, A. Wiesmann, and U. Wegmüller, "GAMMA's 887 portable radar interferometer," Proc. 13th FIG Symp. Deform. Meas. 888 Anal., 2008, pp. 1-10.

[29] L. Pipia, "Polarimetric differential SAR interferometry with ground- 890 based sensors," Ph.D. dissertation, Universitat Politècnica de Catalunya, 891 Barcelona, Spain, 2009.

[30] K. Lukin and A. Mogyla "Monitoring of St. Sophia Cathedral interior 893 using Ka-band ground based noise waveform SAR," in Proc. 6th Radar 894 Conf., (EURAD'09), Rome, Italy, 2009, pp. 215-217.

[31] C. Del Ventisette et al., "Using ground-based radar interferometry during 896 emergency: The case of the A3 motorway (Calabria Region, Italy) threat- 897 ened by a landslide," Natural Hazards Earth Syst. Sci., vol. 11, no. 9, 898 pp. 2483-2495, Sep. 2011.

[32] S. Rodelsperger, A. Coccia, D. Vicente, and A. Meta, "Introduction to 900 the new metasensing ground-based SAR: Technical description and data 901 analysis," in Proc. IEEE Int. Geosci. Remote Sens. Symp., Jul. 2012, 902 pp. 4790-4792.

[33] H. Lee, S. Member J.-H. Lee, S. Member, and K.-E. Kim "Development 904 of a truck-mounted arc-scanning synthetic aperture radar," IEEE Trans. 905 Geosci. Remote Sens., vol. 52, no. 5, pp. 2773-2779, May 2014.

[34] N. Harries, D. Noon, H. Pritchett, and D. Bates, "Slope stability radar for 907 managing rock fall risks in open cut mines," in Proc. 3rd CANUS Rock 908 Mech. Symp., Toronto, ON, Canada, May 2009, vol. 2009, pp. 1-8.

[35] D. Mecatti et al., "Monitoring open-pit quarries by interferometric radar 910 for safety purposes," in Proc. 7th Eur. Radar Conf., Paris, France, Oct. 911 2010, pp. 37-40.

[36] P. Farina et al. "IBIS-M: An innovative radar for monitoring slopes in 913 open-pit mines," in Proc. Int. Symp. Rock Slope Stabil. Open Pit Mining 914 Civil Eng., Vancouver, BC, Canada, 2011.

[37] P. Farina and N. Coli, "Efficient real time stability monitoring of mine walls : The Çöllolar mine case study," in Proc. Int. Mining Congr. Exhib. Turkey, Antalya, Turkey, 2013, pp. 111-117.

[38] D. Tarchi et al., "On the use of ground-based SAR interferometry 919 for slope failure early warning: The Cortenova rock slide (Italy)," in 920 Landslides, 2005, pp. 337-342.

[39] D. Tarchi, "Monitoring landslide displacements by using ground-based 922 synthetic aperture radar interferometry: Application to the Ruinon land- 923 slide in the Italian Alps," J. Geophys. Res., vol. 108, no. B8, p. 2387, 924 2003.

[40] N. Casagli, F. Catani, C. Del Ventisette, and G. Luzi, "Monitoring, pre- 926 diction, and early warning using ground-based radar interferometry," 927 Landslides, vol. 7, no. 3, pp. 291-301, May 2010.

[41] M. Pieraccini et al., "Remote sensing of building structural displace- 929 ments using a microwave interferometer with imaging capability," NDT \& 930 E Int., vol. 37, no. 7, pp. 545-550, 2004.

\section{. 8 (1)

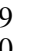

(1)
7

2


[42] L. Pipia et al., "Polarimetric differential SAR interferometry: First results with ground-based measurements," IEEE Geosci. Remote Sens. Lett., vol. 6, no. 1, pp. 167-171, Jan. 2009.

[43] M. Crosetto, O. Monserrat, G. Luzi, M. Cuevas-González, and N. Devanthéry, "Discontinuous GBSAR deformation monitoring," ISPRS J. Photogramm. Remote Sens., vol. 93, pp. 136-141, Jul. 2014.

[44] D. Tarchi, E. Ohlmer, and A. Sieber, "Monitoring of structural changes by radar interferometry," Res. Nondestruct. Eval., vol. 9, no. 4, pp. 213-225, Jan. 1997.

[45] O. Montserrat, "Deformation measurement and monitoring with GroundBased SAR," Ph.D. dissertation, Institute of Geomatics, Barcelona, Spain, 2012.

[46] L. Noferini, D. Mecatti, G. Macaluso, M. Pieraccini, and C. Atzeni, "Monitoring of Belvedere Glacier using a wide angle GB-SAR interferometer," J. Appl. Geophys., vol. 68, no. 2, pp. 289-293, Jun. 2009.

[47] D. Tarchi, "Monitoring landslide displacements by using ground-based synthetic aperture radar interferometry: Application to the Ruinon landslide in the Italian Alps," J. Geophys. Res., vol. 108, no. B8, p. 2387, 2003.

[48] G. Herrera et al., "A landslide forecasting model using ground based SAR data: The Portalet case study," Eng. Geol., vol. 105, no. 3-4, pp. 220-230, May 2009.

[49] G. Barla, F. Antolini, M. Barla, E. Mensi, and G. Piovano, "Monitoring of the Beauregard landslide (Aosta Valley, Italy) using advanced and conventional techniques," Eng. Geol., vol. 116, no. 3-4, pp. 218-235, Nov. 2010.

[50] K. Takahashi, M. Matsumoto, and M. Sato, "Continuous observation of natural-disaster-affected areas using ground-based SAR interferometry," IEEE J. Sel. Topics Appl. Earth Observ. Remote Sens., vol. 6, no. 3, pp. 1286-1294, Jun. 2013.

[51] O. Monserrat, M. Crosetto, and G. Luzi, "A review of ground-based SAR interferometry for deformation measurement," ISPRS J. Photogramm. Remote Sens., vol. 93, pp. 40-48, Jul. 2014.

[52] R. Iglesias et al., "Ground-based polarimetric SAR interferometry for the monitoring of Terrain displacement phenomena. Part I: Theoretical description," to be published.

[53] V. D. Navarro-Sanchez, J. M. Lopez-Sanchez, and L. Ferro-Famil, "Polarimetric approaches for persistent scatterers interferometry," IEEE Trans. Geosci. Remote Sens., vol. 52, no. 3, pp. 1667-1676, Mar. 2014.

[54] R. Iglesias et al., "Phase quality optimization in polarimetric differential SAR interferometry," IEEE Trans. Geosci. Remote Sens., vol. 52, no. 5, pp. 2875-2888, May 2014.

[55] R. Iglesias et al., "Polarimetric optimization of temporal sublook coherence for DInSAR applications," IEEE Geosci. Remote Sens. Lett., vol. 12, no. 1, pp. 87-91, Jan. 2015.

[56] R. Hanssen, Radar Interferometry: Data Interpretation and Error Analysis. Norwell, MA, USA: Kluwer, 2001.

[57] J. Marturià, O. Mora, D. Xifre, P. Martínez, and A. Roca, "DInSAR techniques versus high topographic leveling surveys: The subsidence phenomena in Sallent," in Proc. ECONGEO'06, Barcelona, Spain, 2006.

[58] O. Mora, R. Arbiol, and V. Pala, "ICC's project for DInSAR terrain subsidence monitoring of the Catalonian territory," in Proc. IEEE Int. Geosci. Remote Sens. Symp., 2007, pp. 4953-4956.

[59] L. Pipia, X. Fabregas, A. Aguasca, and C. Lopez-Martinez, "Atmospheric artifact compensation in ground-based DInSAR applications," IEEE Geosci. Remote Sens. Lett., vol. 5, no. 1, pp. 88-92, Jan. 2008.

[60] R. Iglesias, "Atmospheric phase screen compensation in ground-based SAR with a multiple-regression model over mountainous regions," IEEE Trans. Geosci. Remote Sens., vol. 52, no. 5, pp. 2436-2449, May 2014.

[61] L. Pipia, X. Fabregas, A. Aguasca, and C. Lopez-Martinez, "Polarimetric temporal analysis of urban environments with a ground-based SAR," IEEE Trans. Geosci. Remote Sens., vol. 51, no. 4, pp. 2343-2360, Apr. 2013.

[62] R. Touzi, A. Lopes, J. Bruniquel, and P. Vachon, "Coherence estimation for SAR imagery," IEEE Trans. Geosci. Remote Sens., vol. 37, no. 1, pp. 135-149, Jan. 1999.

[63] N. Santacana, "Estudi dels grans esllavissaments d'Andorra: Els casos del Forn i del vessant d'Encampadana." Ph.D. dissertation, Universitat Politècnica de Catalunya (UPC), Barcelona, Spain, 1994.

[64] I. Torrebadella et al., "El Deslizamiento del Forn de Canillo en Andorra. Un Ejemplo de Gestión del Riesgo Geológico en Zonas Habitadas en Grandes Deslizamientos," in Proc. 7th Simposio Nacional sobre Taludes y Laderas Inestables, Barcelona, Spain, 2009, pp. 403-414.

[65] P. Blanco-Sánchez, J. J. Mallorquí, S. Duque, and D. Monells, "The Coherent Pixels Technique (CPT): An advanced DInSAR technique for nonlinear deformation monitoring," Pure Appl. Geophys., vol. 165, no. 6, pp. 1167-1193, Aug. 2008.

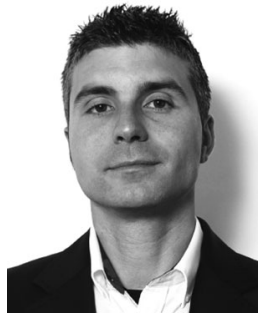

Rubén Iglesias (S'12) was born in Barcelona, Spain, 1009 in 1982. He received the M.Sc. degree in telecommu- 1010 nication engineering from the Universitat Politècnica 1011 de Catalunya (UPC), Barcelona, Spain, in 2008. He 1012 is currently pursuing the Ph.D. degree from UPC, 1013 focused on the development of advanced differen- 1014 tial synthetic aperture radar interferometry (DInSAR) 1015 and polarimetric DInSAR (PolDInSAR) techniques 1016 for the detection, monitoring, and characterization of 1017 slow-moving landslides with both orbital and ground- 1018 based SAR (GB-SAR) data.

1019

From June 2009 to June 2010, he was with the Active Remote Sensing 1020 Unit, Institute of Geomatics, Barcelona, Spain, working in several projects 1021 related with the application of DInSAR to terrain-deformation monitoring with 1022 orbital and GB-SAR data. From June 2010 to March 2014, he was with the 1023 Signal Theory and Communications Department (TSC), UPC, working as a 1024 Research Assistant in the framework of DInSAR and GB-SAR DInSAR appli- 1025 cations. In April 2014, he joined Altamira Information, an experienced Earth 1026 Observation Company in Barcelona dedicated to provide ground displacement 1027 measurements solutions by using DInSAR techniques.

1028

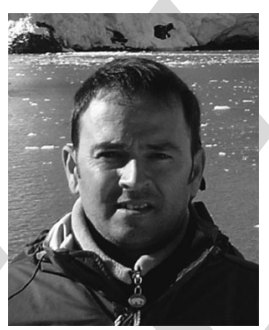

Albert Aguasca (S'90-M'94) was born in 1029 Barcelona, Spain, in 1964. He received the M.Sc. 1030 and $\mathrm{Ph} . \mathrm{D}$. degrees in telecommunication engineering 1031 from the Universitat Politècnica de Catalunya (UPC), 1032 Barcelona, Spain, in 1989 and 1993, respectively. 1033

Since 1995, he has been an Associate Professor 1034 with the School of Telecommunications Engineering, 1035 UPC. His teaching activities involve RF and 1036 microwave circuits for communications and radio 1037 navigation systems. He has published more than 1038 40 papers on microwave synthetic aperture radar, 1039 radiometer systems, and microwave circuits. His research interests include the 1040 design and development of synthetic aperture radar and microwave radiometer 1041 systems for unmanned aerial vehicle (UAV) platforms.

1042

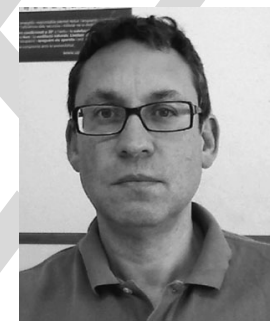

Xavier Fabregas (S'89-M'93) received the B.S. 1043 degree in physics from Barcelona University, 1044 Barcelona, Spain, in 1988, and the Ph.D. degree in 1045 applied sciences from the Universitat Politècnica de 1046 Catalunya (UPC), Barcelona, Spain, in 1995.

In 1990, he joined the Photonic and 1048 Electromagnetic Engineering Group, Signal 1049 Theory and Communications Department, UPC. 1050 Since 1996, he has been an Associate Professor 1051 with the UPC. In 2001, he spent an eight-month 1052 sabbatical with the Microwaves and Radar Institute 1053 (HR), German Aerospace Agency (DLR), Oberpfaffenhofen, Germany. He 1054 has published 26 international journal papers and more than 106 conference 1055 proceedings and has received a patent. He is a Reviewer in several international 1056 journals. His research interests include polarimetric-retrieval algorithms, 1057 polarimetric calibration and speckle models, GB SAR sensors and their 1058 applications, and time series for multidimensional SAR data applications for 1059 urban and terrain deformation monitoring.

1060

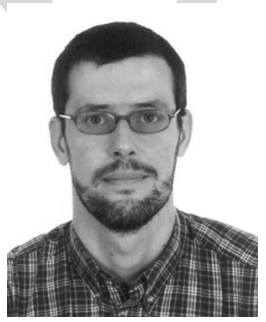

Jordi J. Mallorqui (S'93-M'96-SM'13) was born in 1061 Tarragona, Spain, in 1966. He received the Ingeniero 1062 and Doctor Ingeniero degrees in telecommunica- 1063 tions engineering from the Universitat Politècnica 1064 de Catalunya (UPC), Barcelona, Spain, in 1990 and 1065 1995, respectively. 1066

Since 1993, he has been teaching with the School 1067 of Telecommunications Engineering of Barcelona, 1068 UPC, first as an Assistant Professor, later in 19971069 as an Associate Professor, and since 2011 as a Full 1070 Professor. His teaching activity involves microwaves, 1071 radionavigation systems, and remote sensing. He spent a sabbatical year 1072 with the Jet Propulsion Laboratory, Pasadena, CA, USA, in 1999, working 1073 on interferometric airborne synthetic aperture radar (SAR) calibration algo- 1074 rithms. He is currently working on the application of SAR interferometry to 1075 terrain-deformation monitoring with orbital, airborne, and ground data; ves- 1076 sel detection and classification from SAR images; and 3-D electromagnetic 1077 (EM) simulation of SAR systems. He has published more than 100 papers on 1078 microwave tomography, EM numerical simulation, and SAR processing, inter- 1079 ferometry, and differential interferometry in refereed journals and international 1080 symposia.

1081 


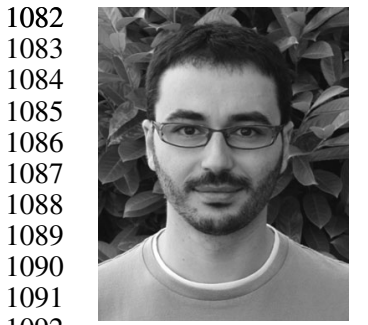

Dani Monells (S'11) was born in Sant Joan de les Abadesses, Spain, in 1981. He received the B.Sc. degree in telecommunication engineering from the Universitat Politècnica de Catalunya (UPC), Barcelona, Spain, in 2008. He is currently pursuing the Ph.D. degree focused on differential synthetic aperture radar interferometry (DInSAR) in orbital platforms, focusing on the exploitation of polarimetric SAR acquisitions (PolSAR), at the Signal Theory and Communications Department (TSC), UPC.

Since 2007, he has been working in several projects for the monitoring of terrain displacements and developing the TSC interferometric chain and processor, in order to give support to the new generation SAR satellites.

1096

1097

1098

1099

1100

1101

1102

1103

1104

1105

1106

1107

1108

1109

1110

1111

1112

1113

1114

1115

1116

1117

1118

1119

1120

1121

1122

1123

1124
From October 2000 to March 2002, he was with the Frequency and Radar Systems Department (HR), German Aerospace Center (DLR), Oberpfaffenhofen, Germany. From June 2003 to December 2005, he has been with the Image and Remote Sensing Group, SAR Polarimetry Holography Interferometry Radargrammetry (SAPHIR) Team, Institute of Electronics and Telecommunications of Rennes (IETR), Rennes, France. In January 2006, he joined the Universitat Politècnica de Catalunya, Barcelona, Spain, as a Ramn-y-Cajal Researcher, where he is currently an Associate Professor in the area of remote sensing and microwave technology. His research interests include SAR and multidimensional SAR, radar polarimetry, physical parameter inversion, digital signal processing, estimation theory, and harmonic analysis.

Dr. López-Martínez is an Associate Editor of the IEEE JOURNAL OF SELECTED TOPICS IN APPLIED EARTH OBSERVATIONS AND REMOTE SENSING and he served as Guest Editor of the European Association for Signal Processing (EURASIP) Journal on Advances in Signal Processing. He has organized different invited sessions in international conferences on radar and SAR polarimetry. He has presented advanced courses and seminars on Student Prize Paper Award at the European Conference on Synthetic Aperture Radar (EUSAR) 2002 Conference and co-authored the paper awarded with the First Place Student Paper Award at the EUSAR 2012 Conference. radar polarimetry to a wide range of organizations and events. He received the

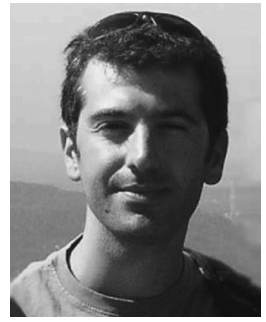

Luca Pipia received the B.S. degree (cum laude) in 1125 electrical engineering from the Università Degli Studi 1126 di Cagliari, Cagliari, Italy, in 2002, and the Ph.D. 1127 degree in polarimetric differential SAR interferome- 1128 try (PolDIInSAR) from the Universitat Politècnica de 1129 Catalunya (UPC), Barcelona, Spain, in 2009.

1130

From June 2001 to December 2001, he was 1131 with the High-Frequency Institute of the German 1132 Aerospace Center (DLR), Oberpfaffenhofen, 1133 Germany, where he worked on land classification 1134 using polarimetric SAR (PolSAR) information. From 1135 2003 to 2009, he was with the Remote Sensing Laboratory, Departament 1136 de Teoria del Senyal i Comunicacions, UPC, where he was deeply involved 1137 in the development and assessment of a novel polarimetric formulation of 1138 coherence-based advanced DinSAR techniques using real ground-based 1139 PolSAR data. Currently, he is with the Remote Sensing Group, Institut 1140 Cartogrfic de Catalunya. His research interests include SAR polarimetry, 1141 differential SAR interferometry, and the retrieval of quantitative information 1142 from hyperspectral visible, near- and thermal-infrared airborne data.

1143

Dr. Pipia has served as a Reviewer for the IEEE JOURNAL OF SELECTED 1144 Topics in Applied Earth ObServations And Remote Sensing, the 1145 IEEE Geoscience And Remote Sensing Letters, and the IEEE 1146 Transactions on Geoscience and Remote Sensing.

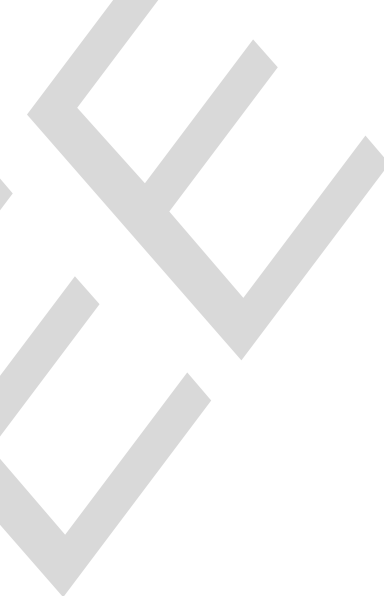

